\title{
Comprehensive FLT3 Analysis in Indian Acute Myeloid Leukaemia
}

\section{Shalvi V. Mehta, Shilin N.Shukla and Hemangini H. Vora*}

Immunohistochemistry \& Flow Cytometry Division, Professor and Head of Medical Oncology Unit III \& Hon. Director, The Gujarat Cancer and Research Institute, NCH Compound, Asarwa, Ahmedabad 380 016, INDIA

\begin{abstract}
Aim: Activating mutations of FLT3 are commonly found in AML patients and reported to be associated with poor clinical outcome. We aimed to evaluate the incidence of FLT3 mutations along with FLT3 mRNA and CD135 protein expression in AML patients of western India and their role in prognosis of disease.

Method: Analysis for the detection of FLT3 internal tandem duplication (ITD), Tyrosine kinase domain (TKD) point mutations and quantification of mRNA level was carried out in total 174 de novo patients diagnosed with acute myeloid leukemia (AML), myelodysplastic syndrome (MDS) and aplastic anemia using PCR and RT-PCR methods. FLT3 protein was quantified by flow cytometry on leukemic blasts.

Results: The incidence of FLT3 ITD, FLT3 TKD mutations and CD135 protein expression was found to be 19\%, $7 \%$ and $62 \%$ respectively in AML patients. In MDS, only FLT3 ITD mutation and CD135 protein over expression could be analyzed, incidence of which was $22 \%$ and $60 \%$. In aplastic anemia, FLT3 mutations, FLT3 mRNA and protein over expression were not detected. FLT3 mutations as well as FLT3 mRNA and protein over expression were prominently noted in AML subtypes associated with myelo-monocytic lineage. CD135 protein over expression was significantly associated with reduced Disease Free Survival (DFS) whereas WBC and blasts emerged as poor prognostic factors with respect to Disease Free Survival (DFS) and Overall Survival (OS) respectively in multivariate analysis.
\end{abstract}

Conclusion: Our data suggest that CD135 receptor protein over expression is a potential prognostic marker as well as molecular target for FLT3 inhibitors in AML patients.

Keywords: FLT3 ITD; FLT3 TKD mutation; FLT3 mRNA; CD135 protein; AML

\section{Introduction}

Fms-like tyrosine kinase 3 (FLT3), also known as stem cell tyrosine kinase 1 (STK1) [1] or fetal liver kinase 2 (flk1) [2], belongs to the group of class III receptor tyrosine kinases along with structurally similar growth receptors such as c-kit, PDGF-R and c-fms [3]. In normal bone marrow, the expression of FLT3 receptor is confined to early hematopoietic progenitor cells $[4,5]$ and mediates stem cell proliferation and differentiation [6]. In normal hematopoiesis, FLT3 ligand binding to the FLT3 receptor causes dimerization of the receptor resulting in the subsequent autophosphorylation, activation of the receptor and induction of multiple intracellular signaling pathways [5].

FLT3 gene is localized on chromosome 13q12 and consists of 24 exons [7]. Internal tandem duplication (ITD) in the juxtamembrane domain - coding sequence, in exons 14 and 15 of FLT3 gene [5], was first identified by Nakao et al. in 1996 [4]. The length of these mutations varies but they are always in frame, thus producing a functional protein [8]. Such insertions leads to FLT3 ligand-independent kinase activation, stimulating proliferation and inhibition of apoptosis and in vitro studies particularly show proliferation of Acute Myeloid Leukemia (AML) cells [9-11]. This mutation is found in approximately $20-30 \%$ of adult AML patients with lower incidence of $5-22 \%$ in pediatric AML patients $[5,10]$. In addition to FLT3 ITD, mis-sense point mutation of D835 in the tyrosine kinase domain (TKD)-coding sequence in exon 20 of FLT3 gene has been identified that also leads to constitute tyrosine phosphorylation $[12,13]$. These point mutations have been reported in $7 \%$ of AML patients $[12,13]$.

Various study groups including few Indian studies have reported the association of activating mutations of FLT3 ITD, with the poor clinical outcome in AML patients [5,14-18], with only few studies reporting absence of association of FLT3 ITD with disease prognosis [19,20].
Studies on FLT3 TKD point mutations show varying results, with few suggesting the role of FLT3 TKD in poor prognosis of AML patients $[16,21]$ while, of few one suggest good prognosis in AML [22]. Very few studies have evaluated the possible association among FLT3 mutations, RNA expression and protein expression [19,23-24]. In our initial study, clinical relevance of FLT3 receptor protein on intact leukemic blasts by flow cytometry was evaluated in Acute Leukemia and found frequent over expression of FLT3 protein in Acute Myeloid Leukemia and B-Acute Lymphoid Leukemia [25]. Further, in a small series of AML, the incidence of protein expression higher than FLT3 mutations was seen. In the present study, we evaluated FLT3 ITD and FLT3 TKD mutations, FLT3 mRNA and correlated with surface FLT3 receptor protein (CD135) in de novo AML, Myelodysplastic Syndrome and Aplastic Anemia. Further, its correlation was evaluated with clinical and haematologic parameters, disease status and treatment offered in AML.

\section{Material and Method}

\section{Patients}

In this study, 174 patients with de novo AML (N=144; AMLM1 [N=27], AMLM2 [N=36], AMLM3 [N=12], AMLM4 [N=18], AMLM5a

${ }^{*}$ Corresponding author: Hemangini $\mathrm{H}$. Vora, Immunohistochemistry \& Flow Cytometry Division, The Gujarat Cancer and Research Institute, NCH Compound, Asarwa, Ahmedabad 380 016, INDIA, Tel: +91-79-2268303; Fax: +91-7922685490; E-mail: incgcri@hotmail.com

Received November 05, 2011; Accepted December 01, 2011; Published December 14, 2011

Citation: Mehta SV, Shukla SN, Vora HH (2012) Comprehensive FLT3 analysis in Indian acute myeloid leukaemia. J Blood Lymph 2:102. doi:10.4172/2165-7831.1000102

Copyright: (C) 2012 Mehta SV, et al. This is an open-access article distributed unde the terms of the Creative Commons Attribution License, which permits unrestricted use, distribution, and reproduction in any medium, provided the original author and source are credited. 
[N=17], AMLM5b [N=14], AMLM6 [N=2], AMLM7 [N=1], unclassified $[\mathrm{N}=17]$ ), Myelodysplastic Syndrome (MDS, N=9; RARS [N=1], RAEBII [N=4] unclassified [N=4]), and Aplastic Anemia [N=21] who were referred to Gujarat Cancer and Research Institute for diagnosis and treatment from 2009 to 2011 were enrolled in the study. Bone marrow $(\mathrm{BM})$ or peripheral blood $(\mathrm{PB})$ samples were collected in ethylenediamine tetraacetic acid (EDTA) vacuette (BD Vacutainer K2 EDTA, BD Franklin Lakes, NJ, USA) at the time of diagnosis from acute leukemia patients as well as from patients with pancytopenia or anemia. Total BM and PB samples obtained from AML were 74 and 70, from MDS, 6 and 3 and from Aplastic anemia patients, 2 and 19, respectively. Follow up samples from 19 patients were available post induction therapy [BM $(\mathrm{N}=07)$ and $\mathrm{PB}(\mathrm{N}=12)$ ] where $6 / 19$ patients showed relapse and 13/19 patients showed remission.

The diagnosis and classification of the acute leukemia samples were based on morphology and cytochemistry according to the French-American-British (FAB) classification and on the presence of maturation and differentiation of antigens as determined by routine immunophenotyping criteria of the European Group for the Immunological Characterization of Leukemias [26]. The patients' detailed clinical history (age, gender, hematological findings, treatment given, etc.) were noted from the case files maintained at the Medical Record Department of the Institute. This study was approved by the Institutional Scientific Review Board and Ethics Committee. Patients provided informed consent to use their sample for the study.

\section{Therapy}

Out of 144 AML patients enrolled in the study, 76 patients underwent treatment out of which 57 were adults and 19 were pediatric patients. Total follow up period was in the range of 1 to 25 months. Mean ( \pm Standard Error) and median Disease Free Survival (DFS) were 4.3 $( \pm 0.73)$ and 0.75 months while mean and median Overall Survival (OS) was $5.39( \pm 0.69)$ and 2.50 months respectively. Treatment protocol was decided by the clinicians of our Institute. Treatment protocol for AML patients were $7+3$ protocol, Berlin Frankfurt Munster (BFM) 93, All Trans Retinoic Acid (ATRA) and / or Arsenic trioxide in combination with anthracycline and Palliative chemotherapy. In $7+3$ protocol, induction was given with daunorubicin for 3 days and cytarabine arabinoside for 7 days, followed by consolidation with cytarabine arabinoside for 5 days every month for 3 months. In BFM 93 protocol, induction was given with Ara-C, daunorubicin and etoposide for 8 days, followed by consolidation with thioguanine, prednisolone, vincristine, doxorubicin, Ara- $\mathrm{C}$, and cyclophosphamide for 6 weeks in low-risk patients and block of Ara-C and mitoxantrone in high risk patients, followed by an intensification block with Ara-C and etoposide for 5 days, followed by cranial irradiation and maintenance with thioguanine, and pulses of Ara-C, for 18 months. In AML M3 FAB subtype, induction was given with daunorubicin for 3 days along with All-trans Retinoic acid (ATRA) / Arsenic trioxide. For consolidation, two blocks each of 21 days including daunorubicin for 3 days with ATRA for two weeks or with Arsenic trioxide, followed by maintenance with $6 \mathrm{MP}$ continuous daily, MTX weekly along with ATRA for 15 days every 3 months or with Arsenic trioxide. Palliative chemotherapy included oral chemotherapy drugs such as 6-Thioguanine (6TG), 6-Mercaptopurine (6MP) and Hydroxyurea or their combinations along with prednisolone and supportive care.

\section{Detection of FLT3 ITD mutation by Polymerase chain reaction (PCR)}

Deoxyribonucleic acid (DNA) was extracted from fresh BM or PB samples with QIAamp DNA mini kit (Qiagen, Germany) according to manufacturer's protocol. For the study of FLT3 ITD mutation, Exons 14 and 15 of FLT3 gene were amplified from genomic DNA using mutation specific primers, Exon 14 Forward (F) 5'-tgtaaaacgacggccagtcaatttaggtatgaaagcc-3' and Exon 15 Reverse (R) 5' gaggaaacagctatgaccctttcagcattttgacggcaacc-3' (Bangalore Genei, India). $\beta$-Actin served as internal control, amplified with following primer sequences F 5'-caagagatggccacggctgct-3' and R 5' - tccttctgcatcctgtcggca-3' (Bangalore Genei, India) and exhibited amplified product of 350 base pair (bp) on agarose gel electrophoresis. Approximately 100ng of genomic DNA was added to PCR mix containing $5 \mu \mathrm{l}$ (10X) PCR buffer, $10 \mu \mathrm{l}$ (5X) Q solution, $2 \mu \mathrm{l} 25 \mathrm{mM} \mathrm{MgCl} 2,1.5 \mu \mathrm{ldNTP}(10 \mathrm{mM}$ each) and $0.5 \mu \mathrm{l} \mathrm{Taq}$ DNA polymerase of PCR core kit (Qiagen, Germany) and $5 \mu \mathrm{l}(0.8 \mu \mathrm{M}$ final concentration) each of forward as well as reverse primers, to make a final volume of $50 \mu \mathrm{l}$. PCR was carried out in Mastercyclergradient (Eppendorf, Germany) with conditions consisting of initial denaturation step at $95^{\circ} \mathrm{C}$ for 2 minutes followed by 40 cycles each of denaturation at $95^{\circ} \mathrm{C}$ for 30 seconds, annealing at $70^{\circ} \mathrm{C}$ for 1 minute and extension at $72^{\circ} \mathrm{C}$ for 1 minute and final extension step at $72^{\circ} \mathrm{C}$ for 10 minutes. Amplified products were resolved on $2 \%$ agarose gels stained with ethidium bromide and visualized on Gel Documentation System (Alpha Innotech Corp., USA). An amplified product of wild type FLT3 was obtained at $366 \mathrm{bp}$. Additional band longer than the wild type bp was considered as FLT3 ITD positive. The additional mutated bands were obtained in the range of approximately 375 to $550 \mathrm{bp}$. Quantity of wild type and mutated fragments was measured as integrated density value (IDV) on Gel Documentation System (Alpha Innotech Corp., USA) using Alphaview software.

\section{Detection of FLT3 point mutations by Reverse transcriptase - Polymerase chain reaction (RT-PCR)}

Ribonucleic acid (RNA) was extracted from the same samples with RNA blood kit (Qiagen, Germany) according to Manufacturer's protocol. To study FLT3 point mutations, Exon 20 of FLT3 gene was amplified from total RNA using primers, Exon $20 \mathrm{~F}$ 5'- ccgccaggaacgtgcttg-3' and Exon 20 R 5'- atgccagggtaaggattcacacc-3' (Bangalore Genei, India). $\beta$-Actin served as internal control with following primer sequences F 5'-gctcgtcgtcgacaacggctc-3' and R 5'-caaacatgatctgggtcatcttctc-3' (Bangalore Genei, India) and amplified product of $353 \mathrm{bp}$. Approximately $1 \mu \mathrm{g}$ of total RNA was added to RT-PCR mix containing $10 \mu \mathrm{l}$ (5X) RT PCR buffer, $10 \mu \mathrm{l}$ (5X) Q solution, $2 \mu \mathrm{dNTP}(10 \mathrm{mM}$ each) and $2 \mu \mathrm{l}$ Enzyme mix (Sensiscript and Omniscript Reverse Transcriptases) from One-Step RT PCR kit (Qiagen, Germany) and $5 \mu \mathrm{l}$ (1.5 $\mu \mathrm{M}$ final concentration) each of forward and reverse primers, to make a final reaction volume of $50 \mu \mathrm{l}$. RT-PCR was carried out in Mastercyclergradient (Eppendorf, Germany) with conditions consisting of initial reverse transcription step at $60^{\circ} \mathrm{C}$ for 30 minutes, activation step at $95^{\circ} \mathrm{C}$ for 15 minutes followed by 30 cycles each of denaturation at $94^{\circ} \mathrm{C}$ for 1 minute, annealing at $60^{\circ} \mathrm{C}$ for 1 minute and extension at $72^{\circ} \mathrm{C}$ for 1 minute and final extension step at $72^{\circ} \mathrm{C}$ for 10 minutes. The $25 \mu \mathrm{l}$ of amplified product was then subjected to digestion with 10 Units of EcoR V restriction endonuclease enzyme (New England Biolabs, USA) and incubated at $37^{\circ} \mathrm{C}$, overnight. Amplified undigested as well as digested products were resolved on $2 \%$ agarose gel in presence of ethidium bromide and visualized on Gel Documentation System (Alpha Innotech Corp., USA). The undigested product was obtained at $238 \mathrm{bp}$ while the digested product bands were obtained at 174 and 64 bp. In case of D835 point mutations, undigested product at 238 bp was obtained in addition to the two digested fragments. Quantity of wild type and mutated fragments was measured as integrated density value (IDV) on Gel Documentation System (Alpha Innotech Corp., USA) using Alphaview software. 


\section{Flow cytometry analysis}

Surface FLT3 receptor protein (CD135) was studied on intact leukemic blasts using bone marrow or peripheral blood samples, by flow cytometric analysis along with immunophenotypic study as described earlier [17].

\section{Statistical analysis}

Statistical analysis was carried out using SPSS statistical software version 17 (SPS Inc, Chicago, IL). Mean, standard error (SE) and median were calculated along with correlation between two parameters which was calculated by Pearson's correlation coefficient (r) method. P value less than 0.05 were considered significant. Disease free survival (DFS) and Overall survival (OS) was calculated according to Kaplan and Meier analysis. Chi square statistics was used to assess the prognostic significance of DFS, OS and significance between two subgroups of various parameters. Multivariate analysis to evaluate the prognostic significance was carried out using Cox regression analysis using method - Forward stepwise (Likelihood Ratio).

\section{Results}

In a total of 144 de novo AML, FLT3 ITD mutation was found in $19 \%$ (27/144) patients. While FLT3 TKD point mutation was observed in 7\% (9/130) patients.

The incidence of FLT3 ITD was higher as compared to FLT3 TKD mutations. Both the mutations were found in only one patient with AML M5b subtype.

\section{Correlation of FLT3 ITD with clinical and hematological parameters}

In relation to clinical parameters (Table 1), similar incidence of FLT3

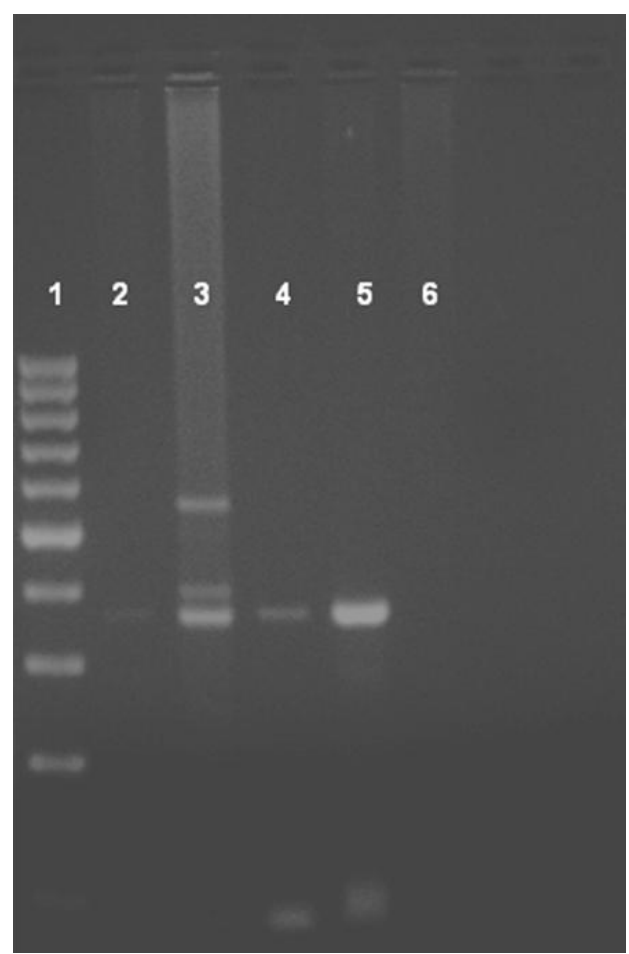

Figure 1: PCR amplification for detection of FLT3 ITD mutation. Lane 1, 100 bp ladder; Lane 2,4,5, FLT3 wild type (366 bp); Lane 3, FLT3 ITD showing two abnormally longer products; Lane 6, Negative control.

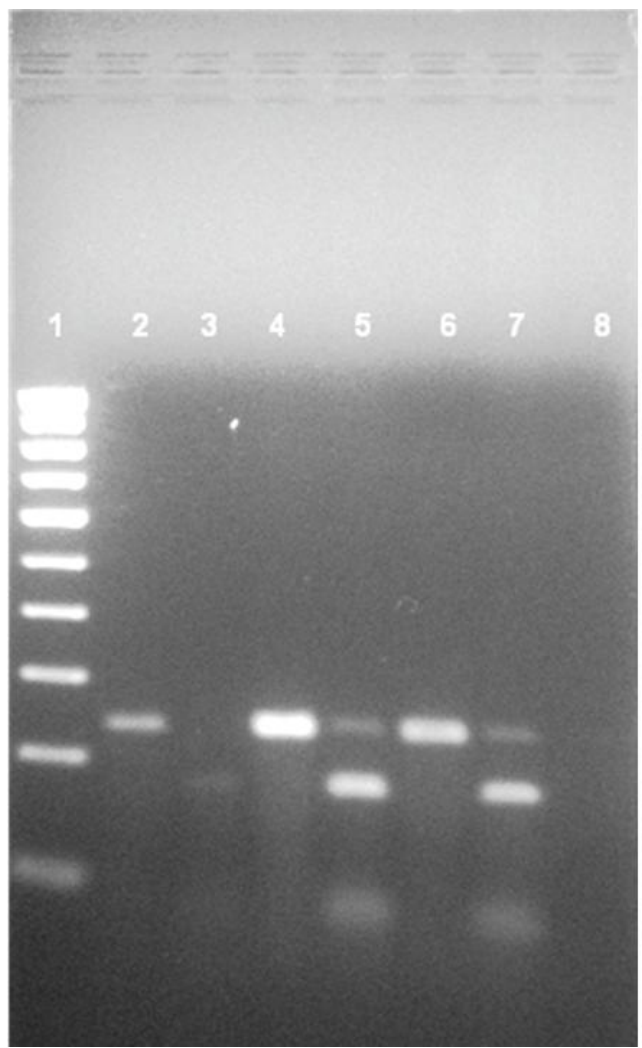

Figure 2: RT PCR amplification and digestion of PCR products by EcoRV enzyme for detection of FLT3 TKD mutation. Lane 1, 100 bp ladder; Lane 2,4,6, FLT3 TKD undigested (238 bp); Lane 3, FLT3 TKD wild type digested (174 and 64 bp); lane 5,7, FLT3 TKD mutation; Lane 8, Negative control.

ITD was noted in three sub groups of age $(<15$ years, $\geq 15$ to $<60$ years and $\geq 60$ years). However, incidence of FLT3 ITD was found to be higher in females $(22 \%, 13 / 58)$ as compared to males $(16 \%, 14 / 86)$.

In relation to hematological parameters, according to $\mathrm{FAB}$ classification, incidence of FLT3 ITD was found to be highest in M6 $(50 \%, 1 / 2)$ followed by M1 $(30 \%, 8 / 27)$, M5b (29\%, 4/14), M3 (25\%, $3 / 12)$, M2 (11\%, 4/36), M4 (11\%, 2/18) and M5a (6\%, 1/17). One patient with AML M7 subtype did not express FLT3 ITD mutation. Further, higher incidence of FLT3 ITD significantly correlated with blasts $\geq 61 \%$ (median as cutoff value) $(27 \%, 20 / 73, \mathrm{P}=0.007)$ and low platelet count $\left(<1.5 \times 10^{5} / \mu \mathrm{l}\right)(21 \%, 27 / 128, \mathrm{P}=0.048)$ as compared to their respective counterparts. A trend of high FLT3 ITD incidence was noted in low Hemoglobin level $(<9.0 \mathrm{gm} / \mathrm{dL})(21 \%, 23 / 110)$, low RBC count $(<3.8 \mathrm{x}$ $\left.10^{6} / \mu \mathrm{l}\right)(20 \%, 27 / 134)$, altered M:E ratio $(19 \%, 18 / 94)$, moderate nuclear to cytoplasmic ratio $(30 \%, 3 / 10)$ and weak staining of Sudan Black B (cytochemical stain) $(24 \%, 4 / 17)$ whereas similar incidence of mutation was observed in subgroups of WBC count. When correlated with disease condition present at the time of diagnosis $(\mathrm{N}=132)$, incidence of FLT3 ITD was found to be highest in patients with pulmonary infiltration $(100 \%, 2 / 2)$ followed by fluid accumulation (pleural, pericardial or ascitic) (29\%,2/7), absence of associated disease condition (20\%, 20/100) and hepatosplenomegaly $(9 \%, 1 / 11)$. No mutation was found in patients presented with lymphadenopathy, gum hypertrophy, granulocytic sarcoma or multiple symptoms.

\section{Correlation of FLT3 ITD mutation to wild type ratio with clinical and hematological parameters}

In patients having FLT3 ITD, ratio of mutant (ITD) to wild type 

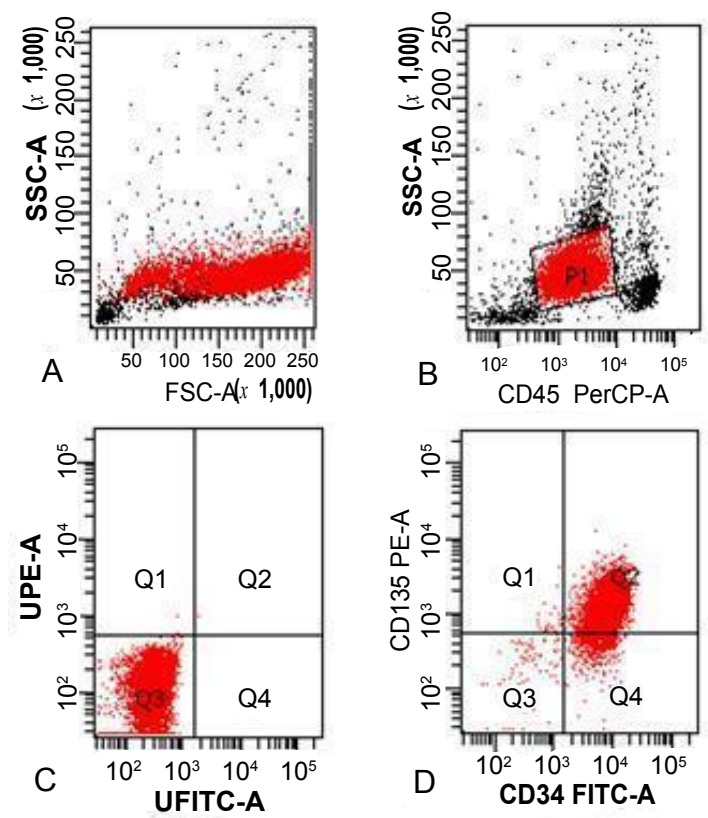

Figure 3: FLT3 receptor protein expression in $\mathrm{PB}$ of acute myeloid leukemia (AML) patient. (A) FSC versus SSC dot plot; (B) myeloblasts gated with CD45 PerCp versus SSC dot plot; (C) isotype control; (D) FLT3 protein expression $(87 \%)$ along with CD34 (99\%) on myeloblasts. FITC, fluoroscein isothiocyanate; $\mathrm{PE}$, phycoerythrin; PerCp, peridinin-chlorophyll.

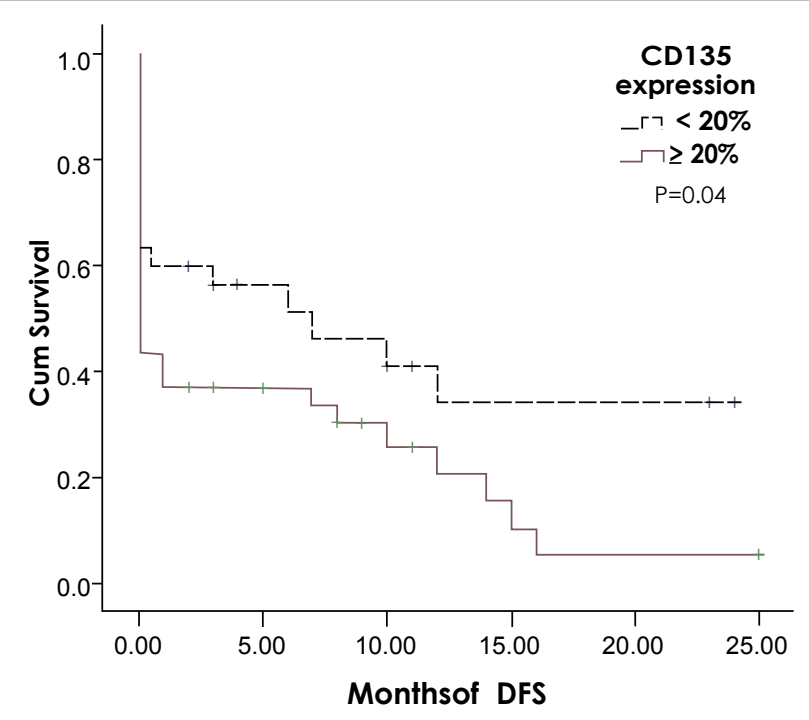

Figure 4: Kaplan-Meier plot of disease-free survival of patients with CD135 protein negativity $(<20 \%)$ and positivity $(>20 \%)$.

(WT) was evaluated by quantification of WT and ITD fragments resolved on agarose gel, where mean ratio of $0.68 \pm 0.07$ (SE of mean) and median ratio 0.66 was observed. These patients were sub-grouped with median ratio as cutoff and correlated with the clinical and hematological parameters (Table 1).

With regards to clinical parameters, a trend of higher mutation ratio $(\geq 0.66)$ was found in patients with age $>60$ years $(67 \%, 2 / 3)$ and in females $(69 \%, 9 / 13)$ as compared to their respective counterparts.
With respect to hematological parameters, higher mutation ratio $(\geq 0.66)$ was observed in AML FAB subtypes M4 $(100 \%, 2 / 2)$, M5a $(100 \%, 1 / 1)$ and M6 $(100 \%, 1 / 1)$, followed by M5b (75\%, 3/4), M1 (50\%, $4 / 8)$ and M2 $(50 \%, 2 / 4)$ and FLT3 ITD mutation ratio < 0.66 in subtype M3 (100\%, 3/3). Further, FLT3 ITD mutation ratio was significantly high in patients having low blast count $(<61 \%)(86 \%, 6 / 7, \mathrm{P}=0.03)$, whereas a trend of high ratio was observed in normal WBC count $\left(4-11 \times 10^{3}\right)$ $(67 \%, 2 / 3)$ and normal Hemoglobin level $(\geq 9.0 \mathrm{gm} / \mathrm{dL})(75 \%, 3 / 4)$. Further, all mutated cases had low platelet $\left(<1.5 \times 10^{5} / \mu \mathrm{l}\right)$ and low RBC count $\left(<3.8 \times 10^{6} / \mu \mathrm{l}\right)$. In correlation with disease condition present at the time of diagnosis, incidence of mutation ratio was high in patients with hepatosplenomegaly $(100 \%, 1 / 1)$ followed by patients with fluid accumulation (pleural, pericardial or ascitic) $(50 \%, 1 / 2)$, pulmonary infiltration $(50 \%, 1 / 2)$ and absence of associated disease condition (50\%, $10 / 20)$.

\section{Correlation of FLT3 TKD point mutation with clinical and hematological parameters}

In relation to clinical parameters (Table 1), higher incidence of FLT3 TKD mutation was observed in age group $\geq 60$ years ( $18 \%, 3 / 17)$ whereas; similar incidence was noted in case of gender subgroups.

In relation to hematological parameters, incidence of FLT3 TKD mutation in AML subtypes was found to be high in M5b (23\%, 03/13) and M4 $(22 \%, 4 / 18)$ while M5a $(6 \%, 1 / 16)$ and M2 $(3 \%, 1 / 30)$ showed low incidence and M1, M3 and M6 did not show TKD mutation. High incidence of FLT3 TKD mutation was noted in low blast count $(<61 \%)$ $(10 \%, 6 / 62)$, high WBC count $(>11000 / \mu \mathrm{l})(8 \%, 9 / 109)$, low Hemoglobin level $(<9.0 \mathrm{gm} / \mathrm{dL})(8 \%, 8 / 101)$, low RBC count $\left(<3.8 \times 10^{6} / \mu \mathrm{l}\right)(7 \%$, 9/123), increased M:E ratio (19\%, 3/16), moderate nuclear to cytoplasmic ratio $(25 \%, 2 / 8)$ and in subgroups of Sudan Black B (cytochemical stain) weak positive $(7 \%, 1 / 15)$ and positive $(6 \%, 4 / 69)$. Similar incidence of FLT3 TKD mutation was noted in the subgroups of platelet count. When correlated with disease condition present at the time of diagnosis, incidence of FLT3 TKD mutation was high in patients with fluid accumulation (pleural, pericardial or ascitic) $(33 \%, 1 / 3)$ followed by hepatosplenomegaly $(12 \%, 1 / 8)$ and patients with absence of associated disease condition $(5 \%, 5 / 95)$.

\section{Incidence of FLT3 RNA transcript level and correlation with the clinical and hematological parameters}

FLT3 RNA was studied in 130 patients and all of them showed FLT3 mRNA expression. Upon quantification it was found in the range of $5 \mathrm{x}$ $10^{4}$ to $19 \times 10^{6}$ with mean \pm SE of $27 \times 10^{5} \pm 28 \times 10^{4}$ as well as median of $16 \times 10^{5}$. The patients were sub grouped considering median level as cutoff level $\left(<16 \times 10^{5}\right.$ and $\left.\geq 16 \times 10^{5}\right)$ (Table 1$)$.

In relation to clinical parameters, incidence of RNA level was found to be similar in subgroups of age and gender.

In relation to hematological parameters, incidence of RNA levels $\geq$ $16 \times 10^{5}$ in AML subtypes was found to be highest in M5b (62\%, 08/13) followed by M3 (60\%, 6/10), M1 (52\%, 13/25), M2 (52\%, 16/30), M4 $(50 \%, 9 / 18)$ and M5a $(44 \%, 7 / 16)$. Two cases of AML M6 expressed FLT3 RNA level $<16 \times 10^{5}$. Further, high incidence of RNA levels $\geq 16 \times 10^{5}$ was noted in high blast count $(\geq 61 \%)(54 \%, 37 / 68)$, normal WBC count (4 to $\left.11 \times 10^{3} / \mu \mathrm{l}\right)(57 \%, 8 / 14)$, low platelet count $\left(<1.5 \times 10^{5}\right)(50 \%, 59 / 117)$, low Hemoglobin level $(<9.0 \mathrm{~g} \mathrm{~m} / \mathrm{dL})(52 \%, 53 / 101)$, high RBC count $(\geq$ $\left.4.8 \times 10^{6} / \mu \mathrm{l}\right)(100 \%, 1 / 1)$, increased M:E ratio $(69 \%, 11 / 16)$, moderate nuclear to cytoplasmic ratio $(75 \%, 6 / 8)$ and in negative subgroup of Sudan 
Citation: Mehta SV, Shukla SN, Vora HH (2012) Comprehensive FLT3 analysis in Indian acute myeloid leukaemia. J Blood Lymph 2:102. doi:10.4172/2165-7831.1000102

Page 5 of 13

\begin{tabular}{|c|c|c|c|c|c|c|c|c|}
\hline & $\mathbf{N}$ & $\begin{array}{l}\text { FLT3 ITD } \\
\text { Positive } \\
\text { N (\%) }\end{array}$ & $\mathbf{N}$ & $\begin{array}{l}\text { FLT3 ITD/WT } \\
\text { ratio } \\
\geq 0.66 \quad \mathrm{~N}(\%)\end{array}$ & $\mathbf{N}$ & $\begin{array}{l}\text { FLT3 TKD muta- } \\
\text { tion } \\
\text { Positive N (\%) }\end{array}$ & $\mathbf{N}$ & $\begin{array}{l}\text { mRNA transcript } \\
\text { level } \\
\geq 16 \times 10^{5} \mathrm{~N}(\%)\end{array}$ \\
\hline Total Patients N (\%) & 144 & $27(19)$ & 27 & $14(52)$ & 130 & $09(07)$ & 130 & $65(50)$ \\
\hline Age & 144 & 27 & 27 & 14 & 130 & 09 & 130 & 65 \\
\hline$<15$ years & 28 & $05(18)$ & 05 & $02(40)$ & 25 & $01(04)$ & 25 & $13(52)$ \\
\hline 15 to 59 years & 96 & $19(20)$ & 19 & $10(53)$ & 88 & $05(06)$ & 88 & $43(49)$ \\
\hline$\geq 60$ years & 20 & $03(15)$ & 03 & $02(67)$ & 17 & $03(18)$ & 17 & $09(53)$ \\
\hline Gender & 144 & 27 & 27 & 14 & 130 & 09 & 130 & 65 \\
\hline Male & 86 & $14(16)$ & 14 & $05(36)$ & 79 & $06(08)$ & 79 & $40(51)$ \\
\hline Female & 58 & $13(22)$ & 13 & $09(69)$ & 51 & $03(06)$ & 51 & $25(49)$ \\
\hline Subtypes & 144 & 27 & 27 & 14 & 130 & 09 & 130 & 65 \\
\hline M1 & 27 & $08(30)$ & 08 & $04(50)$ & 25 & $00(00)$ & 25 & $13(52)$ \\
\hline M2, M2E0, M2B & 36 & $04(11)$ & 04 & $02(50)$ & 30 & $01(03)$ & 30 & $16(53)$ \\
\hline M3 & 12 & $03(25)$ & 03 & $00(00)$ & 10 & $00(00)$ & 10 & $06(60)$ \\
\hline M4, M4E0 & 18 & $02(11)$ & 02 & $02(100)$ & 18 & $04(22)$ & 18 & $09(50)$ \\
\hline M5a & 17 & $01(06)$ & 01 & $01(100)$ & 16 & $01(06)$ & 16 & $07(44)$ \\
\hline M5b & 14 & $04(29)$ & 04 & $03(75)$ & 13 & $03(23)$ & 13 & $08(62)$ \\
\hline M6 & 2 & $01(50)$ & 01 & $01(100)$ & 2 & $00(00)$ & 02 & $00(00)$ \\
\hline M7 & 1 & $00(00)$ & - & - & - & - & - & - \\
\hline Unknown & 17 & $04(24)$ & 04 & $01(25)$ & 16 & $00(00)$ & 16 & $06(38)$ \\
\hline Blasts (Median= $61 \%$ ) & 144 & 27 & 27 & 14 & 130 & 09 & 130 & 65 \\
\hline 更 & 71 & 07 (10)a & 07 & $06(86) c$ & 62 & $06(10)$ & 62 & $28(45)$ \\
\hline$\geq 61$ & 73 & 20 (27)a & 20 & $08(40) c$ & 68 & $03(04)$ & 68 & $37(54)$ \\
\hline 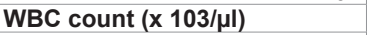 & 144 & 27 & 27 & 14 & 130 & 09 & 130 & 65 \\
\hline$<4$ & 07 & $01(14)$ & 01 & $00(00)$ & 07 & $00(00)$ & 7 & $03(43)$ \\
\hline 4 to 11 & 17 & $03(18)$ & 03 & $02(67)$ & 14 & $00(00)$ & 14 & $08(57)$ \\
\hline$>11$ & 120 & $23(19)$ & 23 & $12(52)$ & 109 & $09(08)$ & 109 & $54(49)$ \\
\hline Platelet count (x 105/ $\mu \mathrm{l})$ & 144 & 27 & 27 & 14 & 130 & 09 & 130 & 65 \\
\hline$<1.5$ & 128 & $27(21) b$ & 27 & $14(52)$ & 117 & $08(07)$ & 117 & $59(50)$ \\
\hline 1.5 to 4.5 & 15 & $00(00) b$ & - & - & 13 & $01(08)$ & 13 & $06(46)$ \\
\hline$>4.5$ & 1 & $00(00) b$ & - & - & - & $-\quad$ - & - & $-\quad 1$ \\
\hline Hemoglobin (gm/dL) & 144 & 27 & 27 & 14 & 130 & 09 & 130 & 65 \\
\hline$<9.0$ & 110 & $23(21)$ & 23 & $11(48)$ & 101 & $08(08)$ & 101 & $53(52)$ \\
\hline$\geq 9.0$ & 34 & $04(12)$ & 04 & $03(75)$ & 29 & $01(03)$ & 29 & $12(41)$ \\
\hline RBC count $(\times 106 / \mu l)$ & 144 & 27 & 27 & 14 & 130 & 09 & 130 & 65 \\
\hline$<3.8$ & 134 & $27(20)$ & 27 & $14(52)$ & 123 & $09(07)$ & 123 & $63(51)$ \\
\hline 3.8 to 4.8 & 9 & $00(00)$ & - & - & 6 & $00(00)$ & 06 & $01(17)$ \\
\hline$>4.8$ & 1 & $00(00)$ & - & - & 1 & $00(00)$ & 01 & $01(100)$ \\
\hline M:E Ratio & 115 & 19 & - & - & 104 & 08 & 104 & 55 \\
\hline Normal $(2: 1-4: 1)$ & 02 & $00(00)$ & - & - & 02 & $00(00)$ & 02 & $02(100)$ \\
\hline Altered & 94 & $18(19)$ & - & - & 83 & $05(06)$ & 83 & $41(49)$ \\
\hline Increased & 16 & $01(06)$ & - & - & 16 & $03(19)$ & 16 & $11(69)$ \\
\hline Decreased & 03 & $00(00)$ & - & - & 03 & $00(00)$ & 03 & $01(33)$ \\
\hline $\mathrm{N}: \mathrm{C}$ ratio & 97 & 18 & - & - & 88 & 07 & 88 & 43 \\
\hline Moderate & 10 & $03(30)$ & - & - & 08 & $02(25)$ & 08 & $06(75)$ \\
\hline High & 87 & $15(17)$ & - & - & 80 & $05(06)$ & 80 & $37(46)$ \\
\hline Cytochemical stain & 102 & 19 & - & - & 92 & 05 & 92 & 43 \\
\hline SBB Negative & 09 & $01(11)$ & - & - & 08 & $00(00)$ & 08 & $05(62)$ \\
\hline SBB weak positive & 17 & $04(24)$ & - & - & 15 & $01(07)$ & 15 & $05(33)$ \\
\hline SBB Positive & 76 & $14(18)$ & - & - & 69 & $04(06)$ & 69 & $33(48)$ \\
\hline Clinical Characteristics & 132 & 25 & 25 & 13 & 120 & 07 & 120 & 58 \\
\hline Lymphadenopathy & 07 & $00(00)$ & - & - & 07 & $00(00)$ & 07 & $03(43)$ \\
\hline Hepatosplenomegaly & 11 & $01(09)$ & 01 & $01(100)$ & 08 & $01(12)$ & 08 & $02(25)$ \\
\hline $\begin{array}{r}\text { Pleural, Pericardial effusions and } \\
\text { Ascitis }\end{array}$ & 07 & $02(29)$ & 02 & $01(50)$ & 03 & $01(33)$ & 03 & $03(100)$ \\
\hline Gum Hypertrophy & 01 & $00(00)$ & - & - & 01 & $00(00)$ & 01 & $00(00)$ \\
\hline Pulmonary infiltration & 02 & $02(100)$ & 02 & $01(50)$ & 02 & $00(00)$ & 02 & $00(00)$ \\
\hline Granulocytic sarcoma & 01 & $00(00)$ & - & - & 01 & $00(00)$ & 01 & $01(100)$ \\
\hline Multiple symptoms & 03 & $00(00)$ & - & - & 03 & $00(00)$ & 03 & $02(67)$ \\
\hline No associated abnormality & 100 & $20(20)$ & 20 & $10(50)$ & 95 & $05(05)$ & 95 & $47(49)$ \\
\hline $\begin{array}{l}\text { mRNA transcript level } \\
\text { (median as cutoff) }\end{array}$ & 130 & 25 & 25 & 12 & 130 & 09 & - & - \\
\hline$<16 \times 10^{5}$ & 65 & $11(17)$ & 11 & $07(64)$ & 65 & $00(00) d$ & - & - \\
\hline$\geq 16 \times 10^{5}$ & 65 & $14(22)$ & 14 & $05(36)$ & 65 & $09(14) d$ & - & - \\
\hline CD135 protein & 144 & 27 & 27 & 14 & 130 & 09 & 130 & 65 \\
\hline Negative & 54 & 08 (15) & 08 & $03(38)$ & 49 & $03(06)$ & 49 & $20(41)$ \\
\hline Positive & 90 & $19(21)$ & 19 & $11(58)$ & 81 & $06(07)$ & 81 & $45(56)$ \\
\hline
\end{tabular}

$a, r=0.22, P=0.007 ; b, r=-0.16, P=0.04 ; c, r=-0.40, P=0.03 ; d, r=0.27, P=0.002$

$P$ value $\leq 0.05$ is significant

WBC, White Blood Cells; RBC, Red Blood Cells

M:E ratio, Myeloid:Erythroid ratio; N:C ratio, Nuclear:Cytoplasmic ratio; SBB, Sudan Black B

Table 1: Correlation of FLT3 ITD, FLT3 mutation to wild type ratio, FLT3 TKD mutation and FLT3 mRNA transcript level with clinical and hematological parameters, clinical characteristics as well as inter-correlation of FLT3 parameters. 
Citation: Mehta SV, Shukla SN, Vora HH (2012) Comprehensive FLT3 analysis in Indian acute myeloid leukaemia. J Blood Lymph 2:102. doi:10.4172/2165-7831.1000102

Page 6 of 13

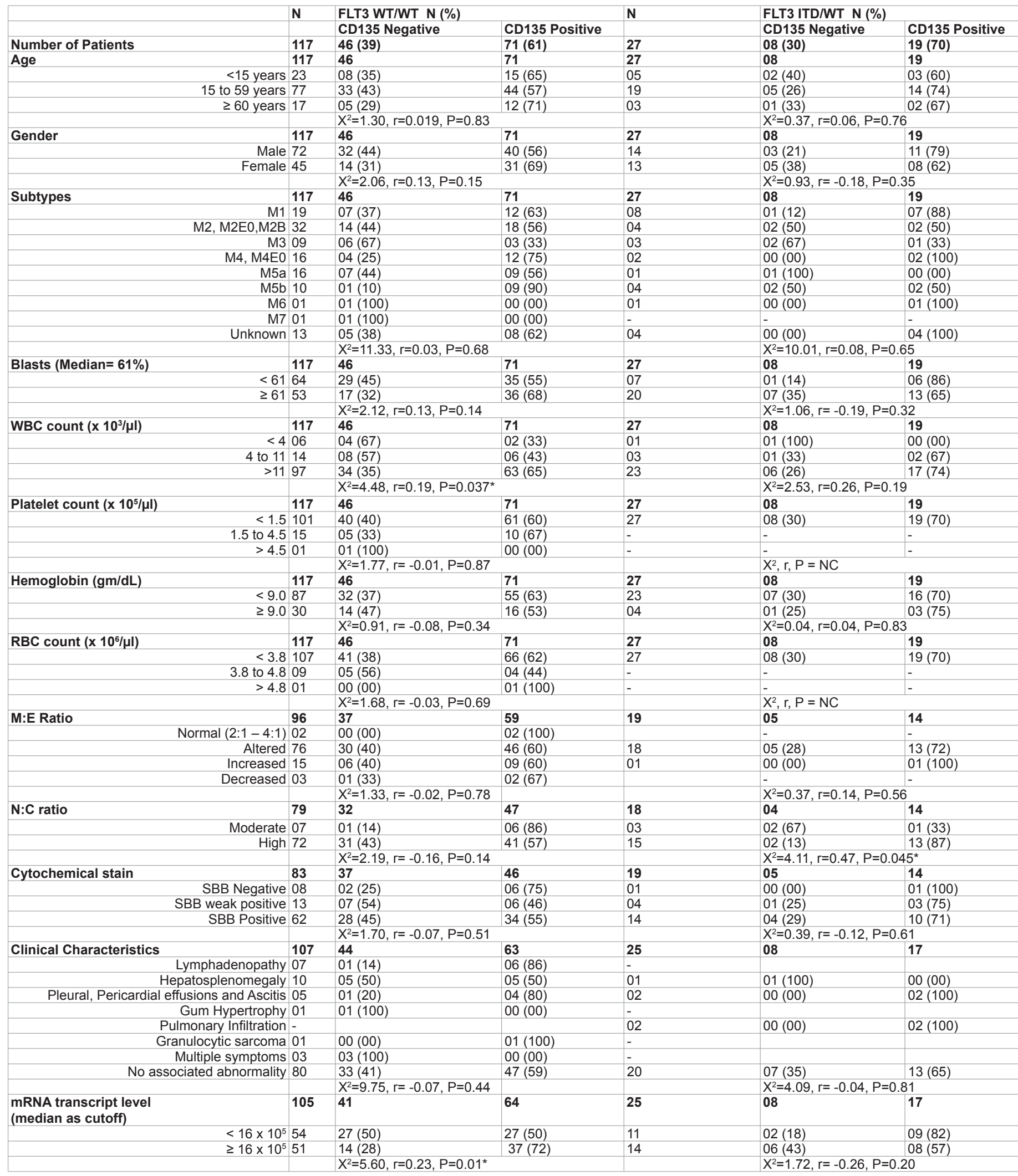

${ }^{*} P$ value $\leq 0.05$ is significant; $N C=$ Non Computable

WBC, White Blood Cells; RBC, Red Blood Cells

$\mathrm{M}: \mathrm{E}$ ratio, Myeloid:Erythroid ratio; $\mathrm{N}: \mathrm{C}$ ratio, Nuclear:Cytoplasmic ratio; SBB, Sudan Black B

Table 2: Correlation of CD135 protein expression within FLT3 WT/WT and FLT3 ITD/WT groups with clinical and hematological parameters, clinical characteristics and FLT3 mRNA transcript level. 
Citation: Mehta SV, Shukla SN, Vora HH (2012) Comprehensive FLT3 analysis in Indian acute myeloid leukaemia. J Blood Lymph 2:102 doi:10.4172/2165-7831.1000102

Page 7 of 13

\begin{tabular}{|c|c|c|c|c|c|c|c|c|}
\hline & $\mathbf{N}$ & Median DFS & Remission & Relapse & $\mathbf{N}$ & Median OS & Alive & Dead \\
\hline \multicolumn{9}{|l|}{ FLT3 ITD } \\
\hline Negative & 64 & 0.75 & $19(30)$ & $45(70)$ & 75 & 3.00 & $50(67)$ & $25(33)$ \\
\hline \multirow[t]{2}{*}{ Positive } & 12 & 0.50 & $04(33)$ & $08(67)$ & 17 & 1.00 & $09(53)$ & $08(47)$ \\
\hline & & \multicolumn{3}{|c|}{ Log Rank $=0.04, d f=1, P=0.84$} & & \multicolumn{3}{|c|}{ Log Rank=1.75, $d f=1, P=0.18$} \\
\hline \multicolumn{9}{|l|}{ FLT3 TKD } \\
\hline Negative & 63 & 1.00 & $20(32)$ & $43(68)$ & 77 & 3.00 & $49(64)$ & $28(36)$ \\
\hline \multirow[t]{2}{*}{ Positive } & 06 & 0.50 & $01(17)$ & $05(83)$ & 06 & 3.50 & $06(100)$ & $00(00)$ \\
\hline & & \multicolumn{3}{|c|}{ Log Rank $=1.08, d f=1, P=0.29$} & & \multicolumn{3}{|c|}{ Log Rank $=2.61, d f=1, P=0.10$} \\
\hline \multicolumn{9}{|l|}{ mRNA Transcript } \\
\hline$<16 \times 10^{5}$ & 37 & 0.00 & $09(24)$ & $28(76)$ & 44 & 3.00 & $29(66)$ & $15(34)$ \\
\hline \multirow{2}{*}{$\geq 16 \times 10^{5}$} & 32 & 2.00 & $12(37)$ & $20(63)$ & 39 & 2.00 & $26(67)$ & $13(33)$ \\
\hline & & \multicolumn{3}{|c|}{ Log Rank=1.09, $d f=1, P=0.29$} & & \multicolumn{3}{|c|}{ Log Rank $=0.002, d f=1, P=0.96$} \\
\hline \multicolumn{9}{|c|}{ 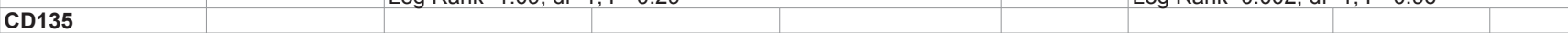 } \\
\hline Negative & 30 & 3.00 & $13(43)$ & $17(57)$ & 37 & 3.00 & $22(60)$ & $15(40)$ \\
\hline \multirow[t]{2}{*}{ Positive } & 46 & 0.00 & $10(22)$ & $36(78)$ & 55 & 2.00 & $37(67)$ & $18(33)$ \\
\hline & & \multicolumn{3}{|c|}{ Log Rank $=3.90, \mathrm{df}=1, \mathrm{P}=0.04^{*}$} & & \multicolumn{3}{|c|}{ Log Rank $=0.20, d f=1, P=0.65$} \\
\hline \multirow{4}{*}{\begin{tabular}{|r|} 
mRNA Transcript \\
$<16 \times 10^{5}$ \\
\end{tabular}} & FLT3 ITD & & & & & & & \\
\hline & Negative 31 & 0.50 & $09(29)$ & $22(71)$ & 36 & 3.00 & $25(69)$ & $11(31)$ \\
\hline & Positive 06 & 0.00 & $00(00)$ & $06(100)$ & 08 & 1.00 & $04(50)$ & $04(50)$ \\
\hline & & \multicolumn{3}{|c|}{ Log Rank $=4.57, \mathrm{df}=1, \mathrm{P}=0.03^{*}$} & & \multicolumn{3}{|c|}{ Log Rank=1.92, $d f=1, P=0.16$} \\
\hline \multirow{4}{*}{$\begin{array}{r}\text { mRNA Transcript } \\
\geq 16 \times 10^{5}\end{array}$} & FLT3 ITD & & & & & & & \\
\hline & Negative 27 & 1.00 & $08(30)$ & $19(70)$ & 31 & 2.00 & $21(68)$ & $10(32)$ \\
\hline & Positive 05 & 3.00 & $04(80)$ & $01(20)$ & 08 & 2.50 & $05(62)$ & $03(38)$ \\
\hline & & \multicolumn{3}{|c|}{ Log Rank=2.55, df=1, $P=0.11$} & & Log Rank=0 & $1, P=0.67$ & \\
\hline mRNA Transcript & FLT3 TKD & & & & & & & \\
\hline$<16 \times 10^{5}$ & Negative 37 & 0.00 & $09(24)$ & $28(76)$ & 44 & 3.00 & $29(66)$ & $15(34)$ \\
\hline mRNA Transcript & FLT3 TKD & & & & & & & \\
\hline$\geq 16 \times 10^{5}$ & Negative 26 & 2.00 & $11(42)$ & $15(58)$ & 33 & 2.00 & $20(61)$ & $13(39)$ \\
\hline & Positive 06 & 0.50 & $01(17)$ & $05(83)$ & 06 & 3.50 & $06(100)$ & $00(00)$ \\
\hline & & Log Rank=2.4 & $1, P=0.12$ & & & Log Rank=3. & $1, P=0.08$ & \\
\hline FLT3 ITD & CD135 & & & & & & & \\
\hline Negative & Negative 26 & 3.00 & $10(38)$ & $16(62)$ & 30 & 3.00 & $19(63)$ & $11(37)$ \\
\hline & Positive 38 & 0.00 & $09(24)$ & $29(76)$ & 45 & 2.00 & $31(69)$ & $14(31)$ \\
\hline & & Log Rank=1.8 & $1, P=0.17$ & & & Log Rank=0. & $1, P=0.85$ & \\
\hline FLT3 ITD & CD135 & & & & & & & \\
\hline Positive & Negative 04 & 3.00 & $03(75)$ & $01(25)$ & 07 & 3.00 & $03(43)$ & $04(57)$ \\
\hline & Positive 08 & 0.00 & $01(12)$ & $07(88)$ & 10 & 1.00 & $06(60)$ & $04(40)$ \\
\hline & & Log Rank=3.2 & $1, P=0.07$ & & & Log Rank=0 & $1, P=0.58$ & \\
\hline mRNA Transcript & CD135 & & & & & & & \\
\hline$<16 \times 10^{5}$ & Negative 17 & 3.00 & $06(35)$ & $11(65)$ & 20 & 3.50 & $11(55)$ & $09(45)$ \\
\hline & Positive 20 & 0.00 & $03(15)$ & $17(85)$ & 24 & 2.50 & $18(75)$ & $06(25)$ \\
\hline & & Log Rank=1.7 & $1, P=0.18$ & & & Log Rank=0 & $1, P=0.31$ & \\
\hline mRNA Transcript & CD135 & & & & & & & \\
\hline$\geq 16 \times 10^{5}$ & Negative 10 & 4.50 & $06(60)$ & $04(40)$ & 13 & 3.00 & $09(69)$ & $04(31)$ \\
\hline & Positive 22 & 0.50 & $06(27)$ & $16(73)$ & 26 & 2.00 & $17(65)$ & $09(35)$ \\
\hline & & Log Rank=3.2 & $1, P=0.07$ & & & Log Rank=0 & $1, P=0.82$ & \\
\hline
\end{tabular}

${ }^{*} P$ value $\leq 0.05$ is significant

DFS, Disease Free Survival; OS, Overall Survival

Table 3: Correlation of FLT3 ITD, FLT3 TKD mutation, mRNA transcript level and CD135 protein expression with clinical outcome.

Black B (cytochemical stain) $(62 \%, 5 / 8)$. When correlated with disease condition present at the time of diagnosis, incidence of RNA level $\geq 16 \mathrm{x}$ $10^{5}$ was high in patients with fluid accumulation (pleural, pericardial or ascitic) $(100 \%, 3 / 3)$ and granulocytic sarcoma $(100 \%, 1 / 1)$ followed by, multiple symptoms $(67 \%, 2 / 3)$, absence of associated disease condition (49\%, 47/95), lymphadenopathy $(43 \%, 3 / 7)$ and hepatosplenomegaly $(25 \%, 2 / 8)$.

\section{Incidence of FLT3 receptor protein and its correlation with clinical and hematological parameters}

FLT3 receptor protein (CD135) levels were estimated by flow cytometer method in 144 AML patients. CD135 over expression $(\geq 20 \%)$ was found in $62 \%(90 / 144)$ of AML patients. In CD135 over expressing group, FLT3 ITD was found in 21\% (19/90) of patients whereas; in CD135 negative group the mutation was found in $15 \%(8 / 54)$ patients (Table 1 ). To determine whether the role of protein over expression in disease progression was dependent on FLT3 ITD, the FLT3 ITD positive and negative groups were further divided into CD135 negative $(<20 \%)$ and positive $(\geq 20 \%)$ groups for comparison in their respective correlation with the clinical and hematological parameters (Table 2).
With respect to clinical parameters, no significant correlation was obtained when CD135 over expression of FLT3 ITD group was compared with that of FLT3 ITD negative group. But trend of higher incidence of CD135 over expression in FLT3 ITD group was noted in the age group of 15 to 59 years $(74 \%, 14 / 19)$ and in males $(79 \%, 11 / 14)$ over negative group.

With respect to hematological parameters, the number in each AML subtype was too small to evaluate statistical significance between CD135 overexpressing FLT3 ITD group and FLT3 ITD negative group. Further, incidence of CD135 over expression was higher in FLT3 ITD group having low blast count $(<61 \%)(86 \%, 6 / 7)$, normal to high WBC count (4 to $11 \times 10^{3}$ and $\left.>11000 / \mu l\right)(67 \%, 2 / 3$ and $74 \%, 17 / 23)$, low platelet count $\left(<1.5 \times 10^{5} / \mu \mathrm{l}\right)(70 \%, 19 / 27)$, low and normal Hemoglobin level $(<9 \mathrm{gm} / \mathrm{dL}$ and $\geq 9 \mathrm{gm} / \mathrm{dL})(70 \%, 16 / 23$ and $75 \%, 3 / 4)$, low RBC count $\left(<3.8 \times 10^{6} / \mu \mathrm{l}\right)(70 \%, 19 / 27)$, altered and increased M:E ratio $(72 \%$, $13 / 18$ and $100 \%, 1 / 1)$, high nuclear to cytoplasmic ratio $(87 \%, 13 / 15)$ and all three subgroups of Sudan Black B stain $(100 \%, 1 / 1 ; 75 \%, 3 / 4$; $71 \%, 10 / 14)$. In relation to the associated disease condition, incidence of CD135 over expression ( $\geq 20 \%)$ in FLT3 ITD group was higher in patients with fluid accumulation (pleural, pericardial or ascitic) $(100 \%$, $2 / 2$ vs. $80 \%, 4 / 5)$ and absence of associated disease condition $(65 \%$, 
$13 / 20$ vs. $59 \%, 47 / 80$ ) whereas incidence of CD135 ( $\geq 20 \%)$ was lower in case of hepatosplenomegaly $(0 \%, 0 / 1$ vs. $50 \%, 5 / 10)$ as compared to the CD135 over expression in FLT3 ITD negative group. Both patients with pulmonary infiltration had mutation with CD135 over expression $(\geq 20 \%)(100 \%, 2 / 2)$ and other subgroups could not be compared due to absence of mutation.

\section{Correlation of FLT3 ITD, TKD mutation with RNA transcript level and protein levels}

The incidence of FLT3 ITD was correlated with RNA transcript level and CD135 protein where, a trend of high incidence of FLT3 ITD was observed in transcript level $\geq 16 \times 10^{5}(22 \%, 14 / 65)$ and CD135 $\geq 20 \%$ $(21 \%, 19 / 90)$ as compared to their respective counterparts (Table 1$)$.

FLT3 ITD to wild type ratio was correlated with RNA transcript level and CD135 protein where, a trend of higher incidence of mutation to wild type ratio $\geq 0.66$ was observed in transcript level $<16(64 \%, 7 / 11)$ and $\mathrm{CD} 135 \geq 20 \%(58 \%, 11 / 19)$ as compared to their respective counterparts (Table 1).

Further, the incidence of FLT3 TKD mutation was correlated with RNA transcript level and CD135 protein where, FLT3 TKD mutation was significantly high in transcript level $\geq 16 \times 10^{5}(14 \%, 9 / 65, \mathrm{P}=0.002)$ while incidence was similar in case of both subgroups of CD135 expression levels (Table 1).

Next, the incidence of RNA level was correlated with CD135 protein where, a trend of high incidence of CD135 protein over expression ( $\geq 20 \%)$ was found $(56 \%, 45 / 81)$ in patients with RNA level $\geq 16 \times 10^{5}$ (Table 1).

Comparing the over expression of CD135 of FLT3 ITD positive and negative groups in correlation with the RNA level, incidence of over expressing CD135 of FLT3 ITD group was found to be high in RNA level $<16 \times 10^{5}(82 \%, 9 / 11)$ (Table 2).

Correlation of FLT3 mutations, FLT3 RNA transcript level and CD135 protein with CD34 expression and leukemia associated immunophenotype (LAP)

FLT3 expression is mainly found on immature and precursor cells and therefore a correlation of FLT3 ITD as well as TKD mutations, RNA level and CD135 with CD34 (a marker of immature cells) was evaluated. Incidence of FLT3 ITD was significantly high in CD34- AML (28\%, $16 / 57, \mathrm{P}=0.02)$ than CD34+ $(13 \%, 11 / 87)$ AML. While incidence of FLT3 TKD mutation, RNA level and CD135 protein expression was found similar in the subgroups of CD34- and CD34+ (data not shown).

Further, FLT3 was correlated with leukemia associated immunophenotype (data not shown). When correlated with the myeloid lineage markers, high incidence of FLT3 ITD was found in CD33- (38\%, $3 / 8)$ as compared to $\mathrm{CD} 33+(18 \%, 24 / 136)$ AML while incidence was similar in case of CD13, MPO and CD117 sub groups. In case of FLT3 TKD mutation, high incidence was noted in CD13+ $(7 \%, 9 / 124)$ and CD33+ $(7 \%, 9 / 123)$ and MPO- $(10 \%, 6 / 57)$ AML as compared to their respective counterparts while incidence of FLT3 TKD mutation was similar in both the subgroups of CD117. High incidence of RNA level was found in CD13- $(67 \%, 4 / 6)$, CD33- $(71 \%, 5 / 7)$ AML as compared to their respective counterparts while incidence was similar in case of CD117 and MPO subgroups. Similar incidence of CD135 over expression was found in subgroups of CD13, CD33, CD117 and MPO.

Aberrant expression of B cell marker CD19 was noted in 19\%
(27/144) and incidence of FLT3 ITD, TKD, RNA level and CD135 protein was found to be similar in both the subgroups of CD19. Aberrant expression of T cell marker CD7 was found in 14\% (19/140) and high incidence of FLT3 ITD $(26 \%, 5 / 19)$ and TKD mutation $(18 \%, 3 / 17)$ was noted in CD7+ AML while similar incidence of RNA level and CD135 protein was found between CD7- and CD7+ AML.

\section{Impact of FLT3 mutations, RNA transcript level and CD135 protein expression on clinical outcome}

Out of 144 patients included in the study, 76 patients underwent treatment out of which 57 were adults and 19 were pediatric patients while 68 out of 144 patients were either lost to follow up or died within a month. Induction remission was achieved in 30\% (23/76) while disease relapse was noted in $70 \%$ (53/76) of AML patients.

According to Kaplan Meier analysis (Table 3), FLT3 ITD showed no correlation with DFS but a trend of increase in incidence of death was seen in FLT3 ITD group $(47 \%, 8 / 17)$ with a decrease in median OS (1 month) as compared to FLT3 ITD negative group (33\%, 25/75 and median OS 3 months).

With regards to FLT3 TKD mutation, patients having FLT3 TKD mutation showed higher incidence of relapse $(83 \%, 5 / 6)$ and reduced median DFS (0.50 month) as compared to patients without TKD mutation (68\%, 43/63 and median DFS 1 month). No such trend was seen with OS.

RNA transcript level was correlated with disease status, where, transcript level $\left(\geq 16 \times 10^{5}\right)$ showed decrease in relapse rate $(63 \%, 20 / 32)$ and increased median DFS (2 vs. 0 months) as compared to low RNA level $\left(<16 \times 10^{5}\right)$ whereas no such trend was observed with OS (Table 3 ).

Similarly patients with CD135 over expression also showed significantly high incidence of relapse $(78 \%, 36 / 46, \mathrm{P}=0.04)$ and reduced median DFS ( 0 vs. 3 months) as compared to CD $135<20 \%$ expression. No such trend was seen with OS.

Further, RNA transcript was divided into FLT3 ITD positive and negative groups. In low FLT3 RNA $\left(<16 \times 10^{5}\right)$ group, FLT3 ITD showed significantly high incidence of relapse $(100 \%, 6 / 6$, Log Rank $=4.57$, $\mathrm{df}=1, \mathrm{P}=0.03$ ) with reduced median DFS ( 0 vs. 0.50 month) and high incidence of death $(50 \%, 4 / 8)$ with reduced median OS ( 1 vs. 3 months) as compared to FLT3 ITD negative patients. No such trend was observed in high FLT3 RNA $\left(\geq 16 \times 10^{5}\right)$ group.

Next, RNA transcript level was divided into FLT3 TKD positive and negative groups. The low FLT3 RNA expression group $\left(<16 \times 10^{5}\right)$ did not have FLT3 TKD mutations but in high FLT3 RNA expression group $\left(\geq 16 \times 10^{5}\right)$, FLT3 TKD showed higher incidence of relapse $(83 \%, 5 / 6)$ with reduced median DFS (0.50 vs. 2 months) as compared to the FLT3 TKD negative group. No such trend was seen with OS in this group.

Further, FLT3 ITD group was divided into CD135 expression $(<20 \%$ and $\geq 20 \%)$, CD135 over expression $(\geq 20 \%)$ showed trend of higher incidence of relapse $(88 \%, 7 / 8$ and $76 \%, 29 / 38)$ and reduced median DFS ( 0 vs. 3 months) in FLT3 ITD positive and negative groups respectively. No such trend was seen with OS.

Next, RNA transcript level was then divided into CD135 expression $(<20 \%$ and $\geq 20 \%)$. CD135 over expression $(\geq 20 \%)$ showed trend of higher incidence of relapse $(73 \%, 16 / 22$ and $85 \%, 17 / 20)$ with reduced median DFS ( 0.50 vs. 4.50 and 0 vs. 3 months) in high $\left(\geq 16 \times 10^{5}\right)$ and low $\left(<16 \times 10^{5}\right)$ FLT3 RNA expression groups respectively, while no such trend was observed in relation to OS. 
Citation: Mehta SV, Shukla SN, Vora HH (2012) Comprehensive FLT3 analysis in Indian acute myeloid leukaemia. J Blood Lymph 2:102. doi:10.4172/2165-7831.1000102

Page 9 of 13

\begin{tabular}{|c|c|c|c|c|c|c|}
\hline & Treatment & Total & Remission & Relapse & Alive & Dead \\
\hline \multicolumn{7}{|l|}{ Flt3 ITD } \\
\hline \multirow[t]{4}{*}{ Negative } & $7+3$ protocol & 35 & $11(31)$ & $24(69)$ & $27(77)$ & $08(23)$ \\
\hline & ATRA / Arsenic trioxide & 05 & $03(60)$ & $02(40)$ & $04(80)$ & $01(20)$ \\
\hline & BFM93 protocol & 10 & $04(40)$ & $06(60)$ & $08(80)$ & $02(20)$ \\
\hline & Palliative Chemotherapy & 14 & $01(07)$ & $13(93)$ & $11(79)$ & $03(21)$ \\
\hline \multirow[t]{5}{*}{ Positive } & $7+3$ protocol & 06 & $01(17)$ & $05(83)$ & $06(100)$ & $00(00)$ \\
\hline & ATRA / Arsenic trioxide & 01 & $01(100)$ & $00(00)$ & $01(100)$ & $00(00)$ \\
\hline & BFM93 protocol & 02 & $02(100)$ & $00(00)$ & $02(100)$ & $00(00)$ \\
\hline & Palliative Chemotherapy & 03 & $00(00)$ & $03(100)$ & $00(00)$ & $03(100)$ \\
\hline & & & \multicolumn{2}{|c|}{$X^{2}=18.58, d f=3, P=0.000^{*}$} & \multicolumn{2}{|c|}{$X^{2}=3.23, d f=3, P=0.35$} \\
\hline \multicolumn{7}{|l|}{ Flt3 TKD } \\
\hline \multirow[t]{4}{*}{ Negative } & $7+3$ protocol & 35 & $10(29)$ & $25(71)$ & $28(80)$ & $07(20)$ \\
\hline & ATRA / Arsenic trioxide & 05 & $04(80)$ & $01(20)$ & $05(100)$ & $00(00)$ \\
\hline & BFM93 protocol & 11 & $06(55)$ & $05(45)$ & $09(82)$ & $02(18)$ \\
\hline & Palliative Chemotherapy & 12 & $00(00)$ & $12(100)$ & $07(58)$ & $05(42)$ \\
\hline \multirow[t]{4}{*}{ Positive } & $7+3$ protocol & 03 & $01(33)$ & $02(67)$ & $03(100)$ & $00(00)$ \\
\hline & BFM93 protocol & 01 & $00(00)$ & $01(100)$ & $01(100)$ & $00(00)$ \\
\hline & Palliative Chemotherapy & 02 & $00(00)$ & $02(100)$ & $02(100)$ & $00(00)$ \\
\hline & & & \multicolumn{2}{|c|}{$\mathrm{X}^{2}, \mathrm{df}, \mathrm{P}=\mathrm{NC}$} & \multicolumn{2}{|c|}{$\mathrm{X}^{2}, \mathrm{df}, \mathrm{P}=\mathrm{NC}$} \\
\hline \multirow{5}{*}{$\begin{array}{l}\text { mRNA transcript level } \\
<16 \times 10^{5}\end{array}$} & & & & & & \\
\hline & $7+3$ protocol & 24 & $06(25)$ & $18(75)$ & $18(75)$ & $06(25)$ \\
\hline & ATRA / Arsenic trioxide & 01 & $00(00)$ & $01(100)$ & $01(100)$ & $00(00)$ \\
\hline & BFM93 protocol & 05 & $03(60)$ & $02(40)$ & $05(100)$ & $00(00)$ \\
\hline & Palliative Chemotherapy & 07 & $00(00)$ & $07(100)$ & $05(71)$ & $02(29)$ \\
\hline \multirow[t]{5}{*}{$\geq 16 \times 10^{5}$} & $7+3$ protocol & 14 & $05(36)$ & $09(64)$ & $13(93)$ & $01(07)$ \\
\hline & ATRA / Arsenic trioxide & 04 & $04(100)$ & $00(00)$ & $04(100)$ & $00(00)$ \\
\hline & BFM93 protocol & 07 & $03(43)$ & $04(57)$ & $05(71)$ & $02(29)$ \\
\hline & Palliative Chemotherapy & 07 & $00(00)$ & $07(100)$ & $04(57)$ & $03(43)$ \\
\hline & & & \multicolumn{2}{|c|}{$X^{2}=22.51, d f=3, P=0.000^{*}$} & \multicolumn{2}{|c|}{$X^{2}=4.55, d f=3, P=0.20$} \\
\hline \multicolumn{7}{|l|}{ CD135 } \\
\hline \multirow[t]{4}{*}{ Negative } & $7+3$ protocol & 18 & $06(33)$ & $12(67)$ & $11(61)$ & $07(39)$ \\
\hline & ATRA / Arsenic trioxide & 04 & $04(100)$ & $00(00)$ & $04(100)$ & $00(00)$ \\
\hline & BFM93 protocol & 04 & $02(50)$ & $02(50)$ & $04(100)$ & $00(00)$ \\
\hline & Palliative Chemotherapy & 04 & $01(25)$ & $03(75)$ & $03(75)$ & $01(25)$ \\
\hline \multirow[t]{5}{*}{ Positive } & $7+3$ protocol & 23 & $06(26)$ & $17(74)$ & $22(96)$ & $01(04)$ \\
\hline & ATRA / Arsenic trioxide & 02 & $00(00)$ & $02(100)$ & $01(50)$ & $01(50)$ \\
\hline & BFM93 protocol & 08 & $04(50)$ & $04(50)$ & $06(75)$ & $02(25)$ \\
\hline & Palliative Chemotherapy & 13 & $00(00)$ & $13(100)$ & $08(62)$ & $05(38)$ \\
\hline & & & \multicolumn{2}{|c|}{$X^{2}=16.03, d f=3, P=0.001^{*}$} & $\mathrm{X}^{2}=3.76$ & \\
\hline
\end{tabular}

${ }^{*} \mathrm{P}$ value $\leq 0.05$ is significant; $\mathrm{NC}=$ Non Computable

Table 4: Correlation of FLT3 ITD, FLT3 TKD mutation, FLT3 mRNA transcript level and CD135 protein expression with clinical outcome with respect to treatment options.

Further, patients with wild type RNA transcript were selected with exclusion of patients with FLT3 ITD and TKD mutation. These patients were further sub grouped according to median cut off level of $14 \times 10^{5}$. In patients with high wild type RNA transcripts $\left(\geq 14 \times 10^{5}\right)$, wild type CD135 protein over expression showed higher incidence of relapse $(78 \%$, 14/18, $\log$ Rank=5.92, $\mathrm{df}=1, \mathrm{P}=0.01)$ than their respective counterpart (data not shown).

\section{Impact of FLT3 mutations, RNA transcript and CD135 expression with treatment on clinical outcome}

In case of correlation of FLT3 ITD with DFS, high remission rate $(\mathrm{P}<0.001)$ was noted in FLT3 ITD group treated with BFM93 $(100 \%, 2 / 2)$ and ATRA / Arsenic trioxide $(100 \%, 1 / 1)$ protocols than $7+3$ protocol and palliative chemotherapy. In case of OS, FLT3 ITD patients treated with $7+3$ protocol, ATRA / Arsenic trioxide and BFM93 protocols responded well and all were alive during study period.

In case of FLT3 TKD mutation, high remission rate was obtained in patients treated with $7+3$ protocol $(33 \%, 1 / 3)$ as compared to BFM93 protocol and palliative chemotherapy whereas the overall survival rate was high with all treatment options viz. $7+3$ protocol $100 \%(3 / 3)$ and BFM93 protocol 100\% (1/1).

In case of high RNA transcript level $\left(\geq 16 \times 10^{5}\right)$, high remission rate was observed with ATRA / Arsenic trioxide protocol $(100 \%, 4 / 4)$ as compared to $7+3$ protocol, BFM93 protocol and palliative chemotherapy and survival rates increased in high RNA level with ATRA / Arsenic trioxide protocol 100\% (4/4) and $7+3$ protocol $(93 \%, 13 / 14)$.
With respect to CD135 over expression ( $\geq 20 \%)$, high remission rate was noted in patients treated with BFM93 protocol $(50 \%, 4 / 8)$ compared to $7+3$ protocol, ATRA / Arsenic trioxide protocol and palliative chemotherapy while high survival rate was seen in patients treated with $7+3$ protocol $96 \%(22 / 23)$ than BFM93, ATRA / Arsenic trioxide protocol and palliative chemotherapy (Table 4 ).

\section{Multivariate Analysis of clinical and hematological parameters along with FLT3 parameters}

Multivariate analysis using cox forward stepwise regression model was carried out to evaluate the prognostic significance of clinical and hematological parameters such as age, gender, AML subtype, blast count, WBC count, platelet count, RBC count and hemoglobin level along with FLT3 ITD, FLT3 TKD point mutation, RNA transcript level and CD135 protein in clinical outcome of patients (Data not shown). High WBC count $(>11000 / \mu \mathrm{l})$ was found to be significant prognostic factor $(\mathrm{P}=0.03)$ for predicting reduced DFS and had DFS shorter than 15 months whereas high blast count $(\geq 61 \%)$ was found as significant prognostic factor $(\mathrm{P}=0.001)$ for poor OS and had OS shorter than 21 months.

\section{Comparison of incidence of FLT3 mutations, RNA transcript level and CD135 expression in Aplastic anemia, Myelodysplastic syndrome and Acute myeloid leukemia patients}

Patients diagnosed with Aplastic Anemia and MDS were compared with the AML patients for the incidence of FLT3 mutations, RNA level and CD135 protein expression (Data not shown).

FLT3 ITD mutation was not found in Aplastic Anemia while it was 
noted in 22\% (2/9) of MDS RAEB-II and 19\% (27/144) of AML patients. In case of FLT3 TKD mutations, Aplastic anemia or MDS patients did not have FLT3 TKD mutation while 7\% (9/130) of AML expressed TKD mutations. Further RNA level $\geq 14 \times 10^{5}$ was not found in Aplastic anemia or MDS cases while in AML it was noted in 54\% (70/130). With respect to $\mathrm{CD} 135$ protein expression, $\mathrm{CD} 135$ protein over expression was not seen in Aplastic Anemia patients while CD135 positivity $(\geq 20 \%)$ was noted in 60\% (3/5) MDS patients and 62\% (90/144) in AML patients.

\section{Discussion}

In this study, we have evaluated clinical relevance of FLT3 ITD and FLT3 TKD point mutations, FLT3 mRNA transcripts and correlated with FLT3 receptor protein determined on leukemic blasts by flow cytometry in patients with Acute Myeloid Leukemia (AML), Myelodysplastic Syndrome (MDS) and Aplastic Anemia. Overall incidence of FLT3 ITD was 19\%, FLT3 TKD mutation was 7\%, high mRNA transcript level was $50 \%$ and CD135 over expression was $62 \%$ in AML patients. In aplastic anemia patients, FLT3 ITD and TKD mutation, high mRNA transcript level as well as CD135 protein over expression was not seen. While, in MDS patients, incidence of FLT3 ITD was 20\%, CD135 over expression was $60 \%$ while only one case was analyzed for FLT3 TKD mutation and mRNA transcript level which were negative and low, respectively.

FLT3 ITD mutations were first detected by Nakao et al. in 1996 reporting approximately $23 \%$ incidence in AML [27] followed by various study groups reporting incidence of FLT3 ITD in the range of 10 to $35 \%$ [8-10,14-16,19,23-24,28-33]. Similar to our study, Indian studies reported incidence of FLT3 ITD in the range of 18 to $21 \%$ in AML M3 [17,34,35] and $19-20 \%$ in AML with or without normal karyotype [18,20,36]. With regards to clinical parameters, incidence of FLT3 ITD in pediatric age group was found to be similar to that of adult age group in AML patients. Contrary to our finding other studies demonstrated low frequency of FLT3 ITD in pediatric patients within the range of 5 to $16 \%$ [36-40] as compared to adults, while only one study demonstrated $40 \%$ incidence in pediatric AML though it was done only in 5 patients [15]. A study on pediatric AML by Iwai et al. [38] suggested that since the internal tandem duplication involved juxtamembrane domain of FLT3 gene and was inframe in pediatric which is similar to adult group; it can be assumed that mutation in children with AML occurred in same manner as in adults. With gender, the incidence of FLT3 ITD tended to be high in females, and similar to our study, two groups show significantly high incidence in females $[9,30]$.

In addition, among hematological parameters significant association of FLT3 ITD was confirmed with higher blast count as seen in other studies $[15,19,23]$ as well as with low platelet count which has also been shown by the study of Schnittger et al. [41] on APL patients. In relation to AML FAB subtypes, high incidence of FLT3 ITD was noted in AML M6 (50\%) followed by M1 (30\%), M5b (29\%), M3 (25\%) while low incidence was noted in M2, M4 and M5a though difference was not significant. In AML M6 subtype, few studies have noted FLT3 ITD mutation in the range of $7 \%$ to $20 \%[15,22,30]$ while majority of the studies have not observed FLT3 ITD mutation in AML M6 $[9,10,16,28,31,32,38]$. High incidence in AML M1, M5b and M3 subtypes could be explained by the theory suggesting that FLT3 blocked the granulocytic differentiation of myeloblastic cells [42] while the expression remains associated with the monocytic differentiation [10,31]. As demonstrated by Munoz et al. [43], the incidence of FLT3 ITD was found more in AML subtypes associated with matured myeloid progenitor cell population which could explain significantly high incidence of FLT3 ITD in CD34 negative population in our study. Further in FLT3 ITD mutated cases, high mutation to wild type ratio was found to correlate significantly with female gender, low blast count $(<61 \%)$ and a trend with normal WBC count and normal Hemoglobin level was noted. In relation to subtypes, high mutation to wild type ratio was found in AML subtypes M4 (100\%), M5a (100\%) and M5b (75\%) and single mutation case of M6 had high mutation ratio. The high incidence of mutation to wild type ratio $(\geq 0.66)$ in monocytic cell lineage confirms the association of constitutive activation of FLT3 in monocytic differentiation. Contrary to our finding, no significant association between FLT3 ITD mutation ratio and gender was noted by study of Gale et al. [8]. However, Kuchenbauer et al. [19], and Thiede et al. [31], have correlated FLT3 ITD mutation ratio with age and not the gender, and observed no significant correlation with respect to age.

Our study demonstrated incidence of FLT3 TKD point mutations in 7\% of patients with AML. Various study groups have reported its incidence in the range of 4 to $11 \%$ in AML [12-13,16,21-22,31-32,44] while Indian studies have reported the incidence in the range of $3-6 \%$ in AML $[18,20,36]$. With respect to clinical and hematological parameters and CD34 expression showed no significant correlation, but a trend of high expression was noted in patients with age $\geq 60$ years, moderate nuclear to cytoplasmic ratio, AML M5b and M4 subtypes. This result is in accordance with other study groups $[10,21,31]$ which suggest the distribution of FLT3 TKD mutation in monocytic subtypes of AML. Therefore, similar to FLT3 ITD, FLT3 TKD mutations also seem to play important role in constitutive activation of FLT3 in leukemic myelomonocytic cell differentiation and proliferation.

In this study, all AML patients showed FLT3 mRNA expression and therefore subgrouped according to median level $16 \times 10^{5}$. No significant correlation was found with clinical and hematological parameters in these two subgroups. With AML subtypes, high incidence of FLT3 transcript level $\geq 16 \times 10^{5}$ was noted in AML M5b followed by M3 subtype which is in line with the theory that FLT3 expression increases in monocytic cell lineage differentiation and proliferation. Few studies have reported high expression of FLT3 mRNA in AML compared to normal BM [19, 23,24,45-46].

Further, 62\% of AML over expressed CD135 protein determined by flow cytometry. Different methodologies have been used for protein detection, such as western blot [45,47-48], flow cytometry method [19,23-24,49,50] and ELIZA [51] and observed over expression of FLT3 protein in 70 to $100 \%$ of AML cases $[4,45,49]$. The advantage of flow cytometry over Western blotting in protein estimation was reported by Wergeland et al. [52]. Our previous study on acute leukemia [25] was the first Indian report on CD135 protein over expression in 82\% of AML, $60 \%$ of B-ALL, and $23 \%$ of T-ALL by flow cytometry.

Our earlier study compared CD135 protein expression with clinical and hematological parameters, so the current study compared CD135 expression with clinical and hematological parameters in two subgroups of FLT3 ITD (mutant and wild type), as the incidence of CD135 over expression was higher in FLT3 ITD group. However, no significant correlation was obtained between these two subgroups in relation to clinical and hematological parameters. Further, in FLT3 ITD negative group, significant higher incidence of CD135 over expression was noted in WBC count $>11,000$ correlates CD135 protein over expression of wild type cases with disease aggressiveness.

These markers when intercorrelated, a trend of high incidence of FLT3 ITD mutation seen in FLT3 mRNA transcript and CD135 over expressing subgroups. Similarly, few studies have shown positive correlation of FLT3 ITD mutation with FLT3 mRNA over expression [23-24] and CD135 protein over expression [23]. In case of mutation to 
wild type ratio, trend of high ratio was found in CD135 over expressing group, and in low FLT3 mRNA transcript level which remained unexplained. Further, the incidence of FLT3 TKD mutation was seen higher in patients with high FLT3 mRNA transcript level while remained similar in subgroups of CD135 protein. Moreover, high FLT3 mRNA transcript level was noted in CD135 over expressing group, similarly, over expression of FLT3 mRNA along with FLT3 protein over expression was reported in AML $[19,23,45]$. Further in FLT3 ITD negative group, incidence of CD135 over expression tended to be significantly high in transcript level $\geq 16 \times 10^{5}$ while a trend of inverse correlation was obtained with FLT3 ITD positive group.

Regards to immunophenotypic markers, a trend of high incidence of FLT3 ITD was noted in CD33- group whereas FLT3 TKD mutations was noted in $\mathrm{CD}_{3} 3^{+}, \mathrm{CD}^{3} 3^{+}$, and MPO AML. Higher incidence of mRNA transcript level was found in $\mathrm{CD}^{-}$and $\mathrm{CD} 33^{-}$AML whereas similar incidence of CD135 over expression was found in subgroups of CD13, CD33, CD117 and MPO. In case of aberrant expression of immunophenotypic markers, incidence of FLT3 ITD and FLT3 TKD mutation were found to be high in $\mathrm{CD}^{+}$group while no trend could be obtained with CD19 subgroups. FLT3 ITD mutant group AML with aberrant $\mathrm{CD}^{+}$expression showed higher relapse rate (75\%) as compared to $\mathrm{CD}^{-}$group $(62 \%)$. This result is in line with studies reporting that $\mathrm{CD} 7$ is aberrantly expressed on blast cells in AML and is associated with a poor prognosis $[53,54]$.

To assess the prognostic significance in univariate analysis, FLT3 mutations, FLT3 mRNA transcript level and CD135 protein expression were correlated with clinical outcome. In relation to DFS, interestingly, only CD135 protein over expression significantly correlated with increased relapse rate with shorter DFS whereas FLT3 TKD mutation and mRNA transcript showed no such trend. No such correlation was found in subgroups of FLT3 ITD. FLT3 ITD showed significant increase in relapse rate and reduced median DFS in patients with FLT3 mRNA transcript level $<16 \times 10^{5}$. While FLT3 TKD mutation showed a trend of higher relapse rate and reduced median DFS in FLT3 mRNA transcript level $\geq 16 \times 10^{5}$ group. CD135 over expression tended to increase relapse rate and reduced median DFS in both subgroups of FLT3 ITD cases and FLT3 mRNA transcripts. Thus, our results demonstrate that in wild type FLT3 group CD135 protein expression is equally important in predicting clinical outcome. These results strengthen findings of our previous study that CD135 protein could be of potential prognostic value in AML [25]. Similarly few studies $[19,24,50]$ have reported high wild type FLT3 expression level as a possible risk factor. In relation to OS, only FLT3 ITD mutant cases showed a trend of increase in incidence of death and decrease in OS. No such correlation was found in subgroups of FLT3 TKD mutations, mRNA transcript level and CD135 protein expression. The results concerning the clinical outcome with respect to presence of FLT3 ITD is varying among different study groups. Most of the studies, including one Indian study group showed significantly reduced DFS and OS [5,14-15,17,32] while few show no correlation with clinical outcome [19]. Some studies, similar to our study, showed no correlation of FLT3 ITD mutation with DFS but a trend of decrease in OS $[9,30]$. Among Indian studies, Dunna et al. [18] showed significantly reduced DFS while Chauhan et al. [20] showed no correlation of FLT3 ITD with DFS. With respect to TKD mutations, some studies, including our study, suggest poor prognosis in relation to DFS [16,21], while few show trend in reduced OS $[21,31]$ and some showed no correlation with clinical outcome $[13,18,32,34]$. Contrary to that only one study by Mead et al. [22] has shown better survival with FLT3 TKD mutations.

Regards to treatment, in FLT3 ITD and high mRNA transcript level groups, increased remission rate was observed when treated with ATRA / Arsenic trioxide and BFM93 protocols. In FLT3 TKD mutation group, remission rates increased with $7+3$ protocol while in CD135 over expressing group, remission rate was high with BFM93 and $7+3$ protocol Overall survival improved in FLT3 ITD, FLT3 TKD mutation and mRNA over expressing groups with all treatment options except palliative chemotherapy and in CD135 over expressing group, overall survival increased with $7+3$ protocol and BFM93 protocol. Our results suggest that standard $7+3$ protocol remain the treatment of choice in a subset of FLT3 TKD mutation, ITD mutation, CD135 over expression and high mRNA transcript level in relation to overall survival. Some clinical trials have suggested use of FLT3 inhibitor along with standard $7+3$ protocol to improve response rate though there is a need to demonstrate prolongation of CR duration and survival in patients receiving FLT3 inhibitors [5556]. Also, in APML patients with FLT3 ITD and RNA transcript level $\geq$ $16 \times 10^{5}$, ATRA / Arsenic trioxide protocol remained treatment of choice. None of the patients with TKD mutation were available for correlation while CD135 over expressing subset of patients showed higher relapse rate with ATRA / Arsenic trioxide protocol and therefore CD135 may be used as a marker for identification of an aggressive phenotype of APML which needs to be confirmed on larger patient series. Studies related to APML patients suggest induction with anthracycline along with ATRA as best option [57] though study by Hong et al. [58] suggest that this option does not benefit patients with FLT3 ITD and that FLT3 inhibitors along with ATRA combined with anthracycline should be the treatment option. Further, BFM93 protocol was effective in pediatric patients with FLT3 ITD mutation, high mRNA transcript level and CD135 over expression while showed high relapse rate with FLT3 TKD mutations, although, studies on pediatric AML treated with BFM demonstrate FLT3 ITD as predictor of poor outcome and suggest need for FLT3 inhibitors to improve prognosis [59]. Therefore, a long term follow up is required to assess the duration of $\mathrm{CR}$ and overall survival with the given treatment options.

In multivariate survival analysis by cox forward stepwise regression model, FLT3 ITD, FLT3 TKD mutation, mRNA transcript level and CD135 protein did not turn out to be an independent prognosticator whereas among all parameters, high WBC count $(\geq 11000)$ emerged as significant predictor of high relapse rate and shorter DFS and, high blast count $(\geq 61 \%)$ was significant predictor of high incidence of death and short overall survival. These findings are consistent with studies which demonstrated WBC count as significant prognostic factor in AML [6061] while blast count was demonstrated to be of prognostic significance for reduced OS in AML patients as shown by Amin et al. [62].

In relation to pre leukemic conditions such as MDS and aplastic anemia, FLT3 ITD incidence of $22 \%$ in MDS is contrary to the findings of few study groups including one Indian study which reported absence of FLT3 ITD in MDS $[32,63,64]$, while two studies showed 2\% incidence $[65,66]$. Incidence of CD135 protein $(60 \%)$ was similar to that found in AML patients. We were unable to evaluate FLT3 TKD mutations or RNA transcript level as enough RNA could not be extracted from the samples due to low blood cell count. In aplastic anemia patients of our study, FLT3 ITD and FLT3 TKD mutations were absent along with low expression of mRNA transcript and CD135 protein. Further, implication of myelosuppressive cytokines in hematopoietic failure $[67,68]$ along with activation of apoptotic pathway and down regulation of genes promoting cell proliferation and cell cycle [69] in aplastic anemia suggests that FLT3 gene expression is down regulated causing low expression of CD135 protein.

In summary, CD135 protein expression emerged as significant 
predictor of DFS in only univariate analysis while WBC and blasts appeared as poor prognostic factors with respect to DFS and OS respectively in multivariate analysis. The presence of FLT3 ITD was found to be more associated with the reduced overall survival of the patients while FLT3 TKD mutation was found to be associated with increased relapse rate and shorter disease free survival. Importantly in FLT3 wild type as well as mutant group, pre-therapeutic CD135 protein over expression predicted poor DFS. Our data suggest that evaluation of CD135 protein over expression at diagnosis can help identify the high risk subset of patients which can be targeted by designing new therapies that include FLT3 inhibitor. Further, CD135 protein estimation by flow cytometry is less time consuming than other methods, it is cost-effective and can be done in association with leukemia immunophenotyping.

\section{Acknowledgement}

We are grateful to Gujarat Cancer Society for funding the project "FLT3 expression in acute myeloid leukemia" (project number UI/03/04) on which this work is based.

\section{References}

1. Small D, Levenstein M, Kim E, Carow C, Amin S, et al. (1994) STK-1, the human homolog of Flk-2/Flt-3, is selectively expressed in CD34+ human bone marrow cells and is involved in the proliferation of early progenitor / stem cells. Proc Nat Acad Sci 91: 459-463.

2. Matthews W, Jordan CT, Wiegand GW, Pardoll D, Lemischka IR, et al. (1991) A receptor tyrosine kinase specific to hematopoietic stem and progenitor cellenriched populations. Cell 65: 1143-1152.

3. Rosnet O, Birnbaum D (1993) Hematopoietic receptors of class III receptor-type tyrosine kinases. Crit Rev Oncog 4: 595-613.

4. Gilliland DG, Griffin JD (2002) The roles of FLT3 in hematopoiesis and leukemia. Blood 100: 1532-1542.

5. Frohling S, Schlenk RF, Breitruck J, Benner A, Kreitmeier S, et al. (2002) Prognostic significance of activating FLT3 mutations in younger adults (16 to 60 years) with acute myeloid leukemia and normal cytogenetics: a study of the AML study group Ulm. Blood 100: 4372-4380.

6. Lyman SD, Jacobsen SE (1998) c-Kit ligand and FLT3 ligand: stem/progenitor cell factors with overlapping yet distinct activities. Blood 91: 1101-1134.

7. Abu-Duhier FM, Goodeve AC, Wilson GA, Care RS, Peake IR, et al. (2001) Genomic structure of human FLT3: Implications for mutational analysis. Br. J Haematol 113: 1076-1077.

8. Gale RE, Green C, Allen C, Mead A, Burnett A, et al. (2008) The impact of FLT3 internal tandem duplication mutant level, number, size, and interaction with NPM1 mutations in a large cohort of young adult patients with acute myeloid leukemia. Blood 111: 2776-2784.

9. Schnittger S, Schoch C, Dugas M, Kern W, Staib P, et al. (2002) Analysis of FLT3 length mutations in 1003 patients with acute myeloid leukemia: correlation of cytogenetics, FAB subtype, and prognosis in the AMLCG study and usefulness as a marker for the detection of minimal residual disease. Blood 100: 59-66.

10. Colovic N, Tosic N, Aveic S, Djuric M, Milic N, et al. (2007) Importance of early detection and follow-up of FLT3 mutations in patients with acute myeloid leukemia. Ann Hematol 86: 741-747.

11. Heldin $\mathrm{CH}$ (1995) Dimerization of cell surface receptors in signal transduction. Cell 80: 213-223.

12. Abu-Duhier FM, Goodeve AC, Wilson GA, Care RS, Peake IR, et al. (2001) Identification of novel FLT-3 Asp835 mutations in adult acute myeloid leukemia. Br J Haematol 113: 983-988.

13. Yamamoto $Y$, Kiyoi H, Nakano Y, Suzuki R, Kodera Y, et al. (2001) Activating mutation of D835 within the activation loop of FLT3 in human hematologic malignancies. Blood 97: 2434-2439.

14. Whitman SP, Archer KJ, Feng L, Baldus C, Becknell B, et al. (2001) Absence of the wild-type allele predicts poor prognosis in adult de novo acute myeloid leukemia with normal cytogenetics and the internal tandem duplication of FLT3: A cancer and Leukemia group B study. Cancer Res 61: 7233-7239.

15. Kottaridis PD, Gale RE, Frew ME, Harrison G, Langabeer SE, et al. (2001) The presence of FLT3 internal tandem duplication in patients with acute myeloid leukemia (AML) adds important prognostic information to cytogenetic risk group and response to the first cycle of chemotherapy: analysis of 854 patients from the United Kingdom Medical Research Council AML10 and 12 trials. Blood 98: 1752-1759.

16. Moreno I, Martin G, Bolufer P, Barragan E, Rueda E, et al. (2003) Incidence and prognostic value of FLT3 internal tandem duplication and D835 mutations in acute myeloid leukemia. Haematologica 88: 19-24.

17. Hasan SK, Sazawal S, Dutta P, Pillai LS, Kumar B, et al. (2007) Impact of FLT3 internal tandem duplications on Indian acute promyelocytic leukemia patients: prognostic implications. Hematology 12: 99-101.

18. Dunna NR, Rajappa S, Digumarti R, Vure S, Kagita S, et al. (2010) Fms like tyrosine kinase (FLT3) and nucleophosmin 1 (NPM1) mutations in de novo normal karyotype acute myeloid leukemia (AML). Asian pacific $\mathrm{j}$ cancer prev 11 : $1811-1816$.

19. Kuchenbauer F, Kern W, Schoch C, Kohlmann A, Hiddemann W, et al. (2005) Detailed analysis of FLT3 expression levels in acute myeloid leukemia. Haematologica 90: 1617-1625.

20. Chauhan P, Bhushan B, Mishra A, Singh L, Saluja S, et al. (2011) Mutation of FLT3 gene in acute myeloid leukemia with normal cytogenetics and its association with clinical and immunophenotypic features. Medical oncology 28: 544-551.

21. Whitman SP, Rupert AS, Radmacher MD, Mrozek K, Paschka P, et al. (2008) FLT3 D835//836 mutations are associated with poor disease-free survival and a distinct gene-expression signature among younger adults with de novo cytogenetically normal acute myeloid leukemia lacking FLT3 internal tandem duplications. Blood 111:1552-1559.

22. Mead AJ, Linch DC, Hills RK, Wheatley K, Burnett AK, et al. (2007) FLT3 tyrosine kinase domain mutations are biologically distinct from and have a significantly more favourable prognosis than FLT3 internal tandem duplications in patients with acute myeloid leukemia. Blood 110: 1262-1270.

23. Peng HL, Zhang GS, Gong FJ, Shen JK, Zhang Y, et al. (2008) Fms-like tyrosine kinase (FLT) 3 and FLT3 internal tandem duplication in different types of adult leukemia: Analysis of 147 patients. Croat Med J 49: 650-659.

24. Ozeki K, Kiyoi H, Hirose Y, Iwai M, Ninomiya M, et al. (2004) Biologic and clinical significance of the FLT3 transcript level in acute myeloid leukemia. Blood 103 1901-1908.

25. Vora HH, Shukla SN, Brahmbhatt BV, Mehta SV, Patel NA, et al. (2010) Clinica relevance of FLT3 receptor protein expression in Indian patients with acute leukemia. Asia-Pacific Journal of Clinical Oncology 6: 306-319.

26. Bene MC, Castoldi G, Knapp W, Ludwig WD, Matutes E, et al. (1995) European Group for the Immunological Classification of Acute Leukemias. Proposals for the immunological classification of acute leukemias. Leukemia 9:1783-1786

27. Nakao M, Yokota S, Iwai T, Kaneko H, Horiike S, et al. (1996) Internal tandem duplication of the flt3 gene found in acute myeloid leukemia. Leukemia 10: 1911 1918.

28. Abu-Duhier FM, Goodeve AC, Wilson GA, Gari MA, Peake IR, et al. (2000) FLT3 internal tandem duplication mutations in adult acute myeloid leukemia define a high-risk group. Br J Haematol 111: 190-195.

29. Kainz B, Heintel D, Marculescu R, Schwarzinger I, Sperr W, et al. (2002) Variable prognostic value of FLT3 internal tandem duplications in patients with de novo AML and a normal karyotype, $t(15 ; 17), t(8 ; 21)$ or inv (16). Hematol J 3: 283-289.

30. Boissel N, Cayuela JM, Preudhomme C, Thomas X, Grardel N, et al. (2002 Prognostic significance of FLT3 internal tandem repeat in patients with de novo acute myeloid leukemia treated with reinforced courses of chemotherapy. Leukemia 16: 1699-1704.

31. Thiede C, Steudal C, Mohr B, Schaich M, Schakel U, et al. (2002) Analysis of FLT3-activating mutations in 979 patients with acute myelogenous leukemia: association with $\mathrm{FAB}$ subtypes and identification of subgroups with poo prognosis. Blood 99: 4326-4335.

32. Sheikha MH, Awan A, Tobal K, Yin JA (2003) Prognostic significance of FLT3 ITD and D835 mutations in AML patients. The Hematology Journal 4: 41-46.

33. Sharkawy NM, Hamid TM (2010) Internal Tandem Duplication of FLT3 Gene in Egyptian Adult Acute Myeloid and Acute Lymphoblastic Leukemia. Journal of American Science 6: 344-350.

34. Matthews V, Thomas M, Srivastava V, George B, Srivastava A, et al. (2007) 
Citation: Mehta SV, Shukla SN, Vora HH (2012) Comprehensive FLT3 analysis in Indian acute myeloid leukaemia. J Blood Lymph 2:102. doi:10.4172/2165-7831.1000102

Impact of FLT3 mutations and secondary cytogenetic changes on the outcome of patients with newly diagnosed acute promyelocytic leukemia treated with a single agent arsenic trioxide regimen. Haematologica 92: 994-995.

35. Sazawal S, Kumar B, Hasan SK, Dutta P, Kumar R, et al. (2009) Haematological \& molecular profile of acute myelogenous leukemia in India. Indian $\mathrm{J}$ Med Res 129: 256-261.

36. Ahmad F, Mandava S, Das BR (2010) Analysis of FLT3 ITD and FLT3 ASP835 mutations in de novo AML: Evaluation of incidence, distribution pattern, correlation with cytogenetics and characterization of internal tandem duplication from Indian population. Cancer Investigation 28: 63-73.

37. Kondo M, Horibe K, Takahashi Y, Matsumoto K, Fukuda M, et al. (1999) Prognostic value of internal tandem duplication of the FLT3 gene in childhood acute myelogenous leukemia. Medical and pediatric oncology 33: 525-529.

38. Iwai T, Yokota S, Nakao M, Okamoto T, Taniwaki M, et al. (1999) Internal tandem duplication of the FLT3 gene and clinical evaluation in childhood acute myeloid leukemia. Leukemia 13: 38-43.

39. Meshinchi S, Woods WG, Stirewalt DL, Sweetser DA, Buckley JD, et al. (2001) Prevalence and prognostic significance of FLT3 internal tandem duplication in pediatric acute myeloid leukemia. Blood 97: 89-94.

40. Krstovski N, Tosic N, Janic D, Dokmanovic L, Kuzmanovic M, et al. (2010) Incidence of FLT3 and nucleophosmin gene mutations in childhood acute myeloid leukemia: Serbian experience and the review of the literature. Med Oncol 27: 640-645.

41. Schnittger S, Bacher U, Haferlach C, Kern W, Alpermann T, et al. (2011) Clinical Impact of FLT3 Mutation load in acute promyelocytic leukemia (APL) with $\mathrm{t}(15 ; 17) / P M L-R A R A$. Haematologica 96:1799-1807

42. Wang L, Xu W, Meng H, Qian W, Mai W, et al. (2010) FLT3 and NPM1 mutations in Chinese patients with acute myeloid leukemia and normal cytogenetics. J Zhejiang Univ Sci B 11: 762-770.

43. Munoz L, Aventin A, Villamor N, Junca J, Acebedo G, et al. (2003) Immunophenotyping findings in acute myeloid leukemia with FLT3 internal tandem duplication. Haematologica 88: 637-645.

44. Bacher U, Haferlach C, Kern W, Haferlach T, Schnittger S (2008) Prognostic relevance of FLT3-TKD mutations in AML: the combination matters - an analysis of 3082 patients. Blood 111: 2527-2537.

45. Carow CE, Levenstein M, Kaufmann SH, Chen J, Amin S, et al. (1996) Expression of the hematopoietic growth factor receptor FLT3 (STK-1/FIk2) in human leukemias. Blood 87: 1089-1096.

46. Birg F, Courcoul M, Rosnet O, Bardin F, Pebusque M, et al. (1992) Expression of the FMS/Kit-like gene FLT3 in human acute leukemias of the myeloid and lymphoid lineages. Blood 80: 2584-2593.

47. Zheng R, Levis M, Piloto O, Brown P, Baldwin B, et al. (2004) FLT3 ligand causes autocrine signaling in acute myeloid leukemia cells. Blood 103: 267-274.

48. Brown P, Levis M, Shurtleff S, Campana D, Downing J (2005) FLT3 inhibition selectively kills childhood acute lymphoblastic leukemia cells with high levels of FLT3 expression. Blood 105: 812-820.

49. Rosnet O, Buhring HJ, Marchetto S, Rappold I, Lavagna C, et al. (1996) Human FLT3/FLK2 receptor tyrosine kinase is expressed at the surface of normal and malignant hematopoietic cells. Leukemia 10: 238-48.

50. Brown P, Alonzo T, Gerbing R, Mclntyre E, Lange B, et al. (2008) High leve expression of wild type FLT3 is associated with poor outcome and selective sensitivity to FLT3 inhibitors in childhood acute myeloid leukemia: a children's oncology group study. 50th ASH Annual Meeting and Exposition, Dec 2008

51. Ravandi F, Jilani I, Eastey E, Kantarjian H, Dey A (2007) Soluble phosphorylated FMS-like tyrosine kinase III. FLT3 protein in patients with acute myeloid leukemia (AML). Leuk Res 31: 791-797.

52. Wergeland $L$ (2007) Flt3 receptor tyrosine kinase in AML and its modulation of the $\mathrm{p} 53 / \mathrm{Hdm} 2 / \mathrm{Bcl}-2$ pathway. Bergen open research archive 2007.

53. Rausei-Mills V, Chang K, Gaal K, Weiss LM, Huang Q (2008) Aberrant expression of CD7 in myeloblasts is highly associated with de novo acute myeloid leukemias with FLT3/ITD mutation. Am J Clin Pathol 129: 624-629.

54. Chang H, Yeung J, Brandwein J, Yi QL (2007) CD7 expression predicts poor disease free survival and post-remission survival in patients with acute myeloid leukemia and normal karyotype. Leukemia Research 31: 157-162.
55. Ravandi F, Cortes J, Jones D, Faderl S, Garcia-Manero G, et al. (2010) Phase I/II Study of Combination Therapy With Sorafenib, Idarubicin, and Cytarabine in Younger Patients With Acute Myeloid Leukemia. J Clin Oncol 28: 1856-1862.

56. Yee KWH, Schittenhelm M, O'Farrell AM, Town A, McGreevey L, et al. (2004) Synergistic effect of SU11248 with cytarabine or daunorubicin on FLT3 ITDpositive leukemic cells. Blood 104: 4202-4209.

57. Wang $Z$ and Chen $Z$ (2008) Acute promyelocytic leukemia: from highly fatal to highly curable. Blood 111: 2505-2515.

58. Hong SD, Kim YK, Kim HN, Lee SR, Ahn JS, et al. (2011) Treatment outcome of all-trans retinoic acid/anthracycline combination chemotherapy and the prognostic impact of FLT3/ITD mutation in acute promyelocytic leukemia patients. Korean J Hematol 46: 24-30.

59. Zwaan C, Meshinchi S, Radich J, Veerman A, Huismans D, et al. (2003) FLT3 internal tandem duplication in 234 children with acute myeloid leukemia: prognostic significance and relation to cellular drug resistance. Blood 102: 2387 2394.

60. Chang H, Salma F, Yi QL, Patterson B, Brien B, et al. (2004) Prognostic relevance of immunophenotyping in 379 patients with acute myeloid leukemia. Leukemia Research 28: 43-48.

61. Meshinchi S and Arceci RJ (2007) Prognostic factors and risk-based therapy in pediatric acute myeloid leukemia. The Oncologist 12: 341-355.

62. Amin HM, Yang Y, Shen Y, Estey EH, Giles FJ, et al. (2005) Having a highe blast percentage in circulation than bone marrow: clinical implications in myelodysplastic syndrome and acute lymphoid and myeloid leukemias. Leukemia 19: 1567-1572.

63. Chaubey R, Sazawal S, Mahapatra M, Saxena R (2009) Low frequency of RAS and absence of FLT3-ITD gene mutations in patients with Myelodysplastic Syndromes in India: AlIMS experience. J Clin Oncol 27: 15S

64. Pinheiro RF, de Sa Moreira E, Silva MR, Alberto FL, Chauffaille M (2008) FLT3 internal tandem duplication during myelodysplastic syndrome follow-up: a marker of transformation to acute myeloid leukemia. Cancer Genet Cytogenet 183: 89-93.

65. Bacher U, Haferlach T, Kern W, Haferlach C, Schnittger S (2007) A comparative study of molecular mutations in 381 patients with myelodysplastic syndrome and in 4130 patients with acute myeloid leukemia. Haematologica 92: 744-752.

66. Bains A, Luthra R, Medeiros J, Zuo Z (2011) FLT3 and NPM1 mutations in Myelodysplastic syndromes: Frequency and potential value for predicting progression to acute myeloid leukemia. American Journal of Clinical Pathology 135: 62-69.

67. Sloand E, Kim S, Maciejewski J, Tisdale J, Follmann D, et al. (2002) Intracellula interferon- $y$ in circulating and marrow $T$ cells detected by flow cytometry and the response to immunosuppressive therapy in patients with aplastic anemia. Blood 100: 1185-1191.

68. Young NS, Maciejewski J (1997) The pathophysiology of acquired aplastic anemia. N Engl J Med 336: 1365-1372.

69. Zeng W, Chen G, Kajigaya S, Nunez O, Charrow A, et al. (2004) Gene expression profiling in CD34 cells to identify differences between aplastic anemia patients and healthy volunteers. Blood 103: 325-332. 